\title{
Stochastic House Appreciation and Optimal Mortgage Lending*
}

\author{
Tomasz Piskorski \\ Columbia Business School \\ tp2252@mail.gsb.columbia.edu
}

\author{
Alexei Tchistyi \\ NYU Stern \\ atchisty@stern.nyu.edu
}

February 2008

\begin{abstract}
Assuming full rationality, we characterize the optimal mortgage contract in a continuous time setting with a risky borrower, costly default, a moral hazard problem between the borrower and the lender, and a stochastic house appreciation. We show that many features of subprime lending observed in practice are consistent with economic efficiency and rationality of both borrowers and lenders. In particular, preferential treatment of subprime borrowers is optimal during the housing boom, while default clustering among subprime borrowers is optimal during the housing slump. We also find that stochastic house appreciation makes it profitable to give loans to subprime borrowers who otherwise would be shut out of the housing market, which generates substantial ex-ante utility gains for these borrowers.
\end{abstract}

*We thank seminar participants at 3rd NYC Real Estate Meeting and UC Berkeley for helpful comments and suggestions. 


\section{Introduction}

The recent housing market crisis has brought attention to the so-called subprime mortgage market, which experienced exponential growth over the past few years. The share of subprime mortgages to total originations increased from $6 \%$ in 2002 to $20 \%$ in 2006. As of 2006, the value of U.S. subprime mortgages was estimated at $\$ 1.5$ trillion, or $15 \%$ of the $\$ 10$ trillion residential mortgage market. ${ }^{1}$ Subprime mortgages account for a significant part of the recent increase in household mortgage debt in the United States, from about $60 \%$ of GDP in 2003 to above $75 \%$ of GDP in $2006 .^{2}$ It is widely believed that subprime lending has played a major role in the housing market meltdown in 2007.

Unlike traditional prime mortgages, subprime mortgages are normally made out to higher-risk borrowers who buy pricey houses relative to their income level and make little or no downpayment. Often, these mortgages come with incentives including low initial teaser rates (which later reset to higher rates), and low "interest only" repayment terms that let borrowers pay only the interest portion of the debt or even less than that. In addition, subprime borrowers often maintain a loan balance above the market value of the home. As a result, subprime mortgage loans have a much higher rate of default than prime mortgage loans.

Because of high default rates among subprime borrowers and big losses among subprime investors, subprime mortgages have caused a storm of controversy and criticism. Some critics accuse subprime lenders of predatory lending to naive borrowers who do not fully understand mortgage terms. Others say that subprime underwriters issued mortgages to people who could not afford to pay them back, and then quickly sold their mortgages to outside investors in the form of mortgage-backed securities. Most critics agree that subprime loans do not make sense and should have not been made in the first place. On the other hand, other experts argue that the fast growth of the subprime market was caused by the fast home price appreciation observed in the beginning of the 21st century.

To better understand the nature of the subprime crisis, it is important to examine what caused the rapid growth of the subprime market before the crisis started. This paper seeks to determine whether subprime lending can be explained by rational behavior of BOTH borrowers and lenders. In particular, can the bubblelike behavior of the housing market, i.e., housing boom followed by housing slump, explain the fast growth of the subprime market during the boom and its meltdown during the slump if both lenders and borrowers have rational expectations about the future states of the housing market? In addition, we partially address the following questions. What should the government do before and during the crisis in the housing market? Does subprime lending exacerbate the "housing bubble"?

To address these questions, we consider a dynamic continuous time model with a risky borrower, stochastic home appreciation, costly liquidation and a moral hazard problem. We adopt a two-step approach. First,

\footnotetext{
${ }^{1}$ See, for example, Agarwal and Ho (August 2007).

${ }^{2}$ The mortgage debt data are from Flow of Funds Accounts of the United States, Federal Reserve Board, and the GDP data are from Bureau of Economic Analysis.
} 
assuming full rationality, we derive an optimal mortgage contract, i.e., the best possible incentive-compatible contract between the borrower and the lender, as a solution to a general dynamic contracting problem. Then we examine whether features of existing mortgage contracts are consistent with the properties of the optimal contract.

Specifically, we consider a continuous-time setting in which a borrower with limited liability needs outside financial support from a risk-neutral lender in order to purchase a house. Home ownership generates for the borrower a public and deterministic utility stream. The borrower's consumption is divided into two categories: "necessary" consumption, which includes grocery food, medicine, transportation and other goods and services essential for the household survival, and "luxury" consumption, which includes everything else. We assume that the borrower is infinitely risk averse with respect to necessary consumption and risk neutral with respect to luxury consumption. The minimum level of necessary consumption is given by an exogenous stochastic process. After paying for his necessary consumption, the borrower is free to allocate the remaining part of his income among luxury consumption, saving and debt repayment. The distribution of the "excess" income, which the borrower can use to pay back his debt, is publicly known, however its realizations are privately observable by the borrower.

We assume that the housing market at time zero is in the boom phase, during which the home appreciates at a constant rate. However, at any time the boom can turn into the slump with a certain probability, in which case the home loses its value and the housing market becomes illiquid. The price process is exogenous, and the borrower and the lender have rational expectations. We assume that the borrower and the lender are sufficiently small so that their actions have no effect on macroeconomic variables such as the market price of the home. ${ }^{3}$

Before the purchase of the house, the borrower and the lender sign a contract that will govern their relationship in the future. The contract specifies transfers between the borrower and the lender, conditional on the history of the borrower's income reports and the state of the housing market, as well as the circumstances under which the lender would foreclose the loan and seize the home. The borrower has limited liability and can default on the mortgage contract at any time. The borrower has also the option to sell the home. We assume that selling the home in the boom phase is more efficient than liquidating it through the repossession process due to associated dead-weight costs.

We characterize the optimal allocation using three state variables: the state of the housing market (i.e., the boom or slump), the market home price, and the borrower's continuation utility (i.e., the expected payoff to the borrower provided he acts optimally given the terms of his contract with the lender). We find that it is optimal to subsidize subprime borrowers, i.e., the borrowers with low continuation utility, during the

\footnotetext{
${ }^{3}$ In a general equilibrium framework, actions of mortgage lenders and homebuyers on the aggregate level can affect macroeconomic variables. However, as long as the economic agents on the individual level have no market power, they should regard macroeconomic variables as exogenous in an equilibrium.
} 
boom. Default clustering among subprime borrowers is optimal during the slump. It is optimal to insure prime borrowers, i.e., the borrowers with high continuation utility, against the slump.

After characterizing the optimal allocation in terms of the continuation utility of the borrower and the lender, we show that the optimal allocation can be implemented using a home equity loan (HEL) with adjustable negative amortization limit with the following features. In the boom phase, the negative amortization limit is increasing with the price of the home and is greater than the value of the home. The mortgage interest rate is increasing with the home price. The subprime borrowers are given additional subsidy during the boom, while the prime borrowers are charged an insurance premium. The slump results in the tightening of the negative amortization limit and default clustering among subprime borrowers. The prime borrowers are partially insured against the slump through a balance reduction.

The features of the optimal mortgage contract can be explained by the incentive-compatibility constraints and the dual optimization objective of the contracting problem: minimization of liquidation inefficiencies and maximization of the value of the option to sell the home in the future at a higher price. The credit line provides flexibility for the borrower to cover possible low income realizations, which in turn lowers chances of default inefficiencies. The credit limit, which is determined by incentive compatibility constraints, takes into account the value of the option. The option value increases with the home price as does the credit limit. During the slump, the option to sell the home loses its value, which results in the credit limit reduction. The interest rate goes up with the home price because the value of the option goes up. The subsidy of the subprime borrowers during the boom is driven by the maximization of the option value, while the default clustering during the slump happens because of the borrower's limited liability and the incentive-compatibility constraints. The insurance of the prime borrowers is explained by the fact that the prime borrowers are not likely to default during the boom, but are more vulnerable during the slump.

The features of our optimal mortgage contract are parallel to many aspects of the subprime lending. Thus, we conclude that subprime lending does not contradict rationality of both borrowers and lenders.

We also find that house appreciation makes it profitable to give loans to subprime borrowers who otherwise would be shut out of the housing market. According to the parametrized example we consider, home ownership generates substantial ex-ante utility gains for the subprime borrowers. Thus, our results provide theoretical evidence that the bubble-like behavior of housing prices can cause rapid growth of the subprime market.

In terms of policy implications, our model suggests that bailing out the most distressed subprime borrowers in the slump phase, is not incentive compatible, as it encourages irresponsible financial behavior in the boom phase. On the other hand, it makes sense to help borrowers who were in good standing before the crisis.

Although we do not consider a general equilibrium model in this paper, we speculate that subprime lending can contribute to the "housing bubble". During the housing boom, the inflow of subprime borrowers into 
the housing market may help sustain house appreciation, possibly driving home prices above the equilibrium level. However, default clustering among subprime borrowers during the housing slump may exacerbate the crisis in the housing market. Thus, the features of subprime lending that are optimal at the individual level may have negative consequences at the aggregate level. Although the borrower and the lender properly factor expectations about home price behavior into the optimal contract, they do not take into account the potential negative externalities that their contract might impose.

\section{Related Literature}

This paper belongs to the growing literature on dynamic optimal security design, which is a part of the literature on dynamic optimal contracting models using recursive techniques that began with Green (1987), Spear and Srivastava (1987), Abreu, Pearce and Stacchetti (1990) and Phelan and Townsend (1991), among many others. Sannikov (2006a) developed continuous-time techniques for a principal-agent problem.

The most closely related paper to ours is Piskorski and Tchistyi (2007) who study the optimal mortgage design in a stationary continuous time setting with volatile and privately observable income of the borrower and a stochastic market interest rate. They show that the optimal mortgage takes form of either an option ARM or a combination of an interest only mortgage with a HELOC, and that default rates and interest rates correlate positively with the market interest rate. In this paper, we assume the interest rate constant and focus on a stochastic house price environment where the borrower has the option to sell the home. The findings of this study are complementary to those of Piskorski and Tchistyi (2007).

The two other studies closely related to ours are DeMarzo and Fishman (2004) and its continuoustime formulation by DeMarzo and Sannikov (2006). These papers study long-term financial contracting in a setting with privately observed cash flows, and show that the implementation of the optimal contract involves a credit line with a constant interest rate and credit limit, long-term debt, and equity. Biais et al. (2006) study the optimal contract in a stationary version of DeMarzo and Fishman's (2004) model and show that its continuous time limit exactly matches DeMarzo and Sannikov's (2006) continuous-time characterization of the optimal contract. Tchistyi (2006) considers a setting with correlated cash flows and shows that the optimal contract can be implemented using a credit line with performance pricing. Sannikov (2006b) shows that an adverse selection problem, due to the borrower's private knowledge concerning the quality of a project to be financed, implies that, in the implementation of the optimal contract, a credit line has a growing credit limit. He (2007) studies the optimal executive compensation in the continuous-time agency model where the manager privately controls the drift of the geometric Brownian motion firm size. Clementi and Hopenhayn (2006), DeMarzo and Fishman (2006), DeMarzo, Fishman, He and Wang (2007) and Philippon and Sannikov (2007) offer theoretical analyses of optimal investment and security design in moral hazard environments. Adrian and Westerfiled (2007) study optimal contracting with moral hazard in a model where the principal and agent have differential beliefs. None of the above studies considers an 
environment with stochastic asset prices and the option to sale the asset.

There is a sizeable real estate finance literature that addresses the design of mortgages in the presence of asymmetric information between the borrower and lender. The bulk of this literature focuses on adverse selection and how it affects the menu of mortgages being offered to borrowers with limited insurance possibilities. Chari and Jagannathan (1989) consider a model with two private types of borrowers, who differ in terms of the riskiness of their potential gains from selling the property, and show that the optimal contract to be chosen by borrowers with larger potential gains involves contractual arrangements such as points ${ }^{4}$ and prepayment penalties together with a "due-on-sale" clause. Brueckner (1994) develops a model in which borrowers self-select into different loans, and shows that the optimal menu of mortgages will induce longer term borrowers to select loans with higher points and a lower coupon. Unlike these two papers, LeRoy (1996) considers a stochastic interest rate environment and finds that, when borrowers refinance optimally, if interest rates fall, the points/coupon choice can at best serve only to separate the least mobile borrower type from all others. Stanton and Wallace (1998) show that in the presence of transaction costs payable by borrowers on refinancing, it is possible to construct a separating equilibrium in which borrowers with differing mobility select fixed rate mortgages with different combinations of coupon rate and points. Posey and Yavas (2001) study how borrowers with different private levels of default risk would self-select between fixed rate mortgages and adjustable rate mortgages, and show the unique equilibrium may be a separating equilibrium in which the high-risk borrowers choose the adjustable rate mortgages, while low-risk borrowers select the fixed rate mortgages. Unlike these papers that focus on adverse selection, Dunn and Spatt (1985) consider a two-period moral hazard model, where future income realizations of borrowers are uncertain and private, and show that the optimal mortgage would involve a due-on-sale clause. In terms of this literature, to our knowledge, our paper is the first study of optimal mortgage design in a dynamic moral hazard environment, and the first study that addresses the optimality of alternative mortgage products.

There is also a sizeable real estate finance literature that studies the optimal strategy of the mortgage borrower in the stochastic house price environment (see for example Kau, Keenan, Mueller, and Epperson (1992) and Deng, Quigley, and Van Order (2000)). These literature however restricts its attention to specific class of contracts and thus, unlike this paper, do not address the question of optimal lending.

A large growing literature focuses on the choice of mortgage contracts as a party of household risk management (for example, Campbell and Cocco (2003)). Unlike our paper, this literature takes a space of contracts as exogenously given, and studies the household choice within this restricted set of contracts.

Another branch of research investigates limited participation models, where housing collateral insulates households from labor income shocks. Lustig and Van Nieuwerburgh (2006) typifies this approach.

The paper is organized as follows. Section 2 presents the continuous-time model with stochastic house

\footnotetext{
${ }^{4}$ Points represent the amount paid either to maintain or lower the interest rate charged.
} 
appreciation. Section 3 describes the dynamic contracting problem. Section 4 derives the optimal contract using the three state variables: the state of the housing market, the market home price and the borrower's continuation utility. Section 5 presents the implementations of the optimal contract using financial arrangements that resemble the ones used in the residential mortgage market. Section 6 concludes.

\section{The Model}

Time is continuous and infinite. There is one borrower (a homebuyer) and one lender (a large financial institution). ${ }^{5}$ The lender is risk neutral, has unlimited capital, and values a stochastic cumulative cash flow $\left\{f_{t}\right\}$ as

$$
E\left[\int_{0}^{\infty} e^{-r} d f_{t}\right]
$$

where $r$ is the discount rate.

The borrower's consumption consists of three categories. The first is "necessary" consumption, which includes grocery food, medicine, transportation, shelter and other goods and services essential for the household survival. The second is housing consumption, which comes from owning or renting a house. Everything else is "luxury" consumption, which, among many other things, may include such items as restaurant dining, vacation trips, buying a new car, et cetera.

The cumulative minimum level of necessary consumption is given by an exogenous stochastic process $\left\{\eta_{t}\right\}$ that incorporates shocks such as medical bills, auto repair costs, fluctuations of food and gasoline prices, and so on. We assume that the borrower is infinitely risk averse with respect to the necessary consumption and risk neutral with respect to the luxury and housing consumption. That is, the borrower's instantaneous utility function is given by

$$
u\left(d C_{t}^{0}, d C_{t}, d C_{t}^{H}\right)=\left\{\begin{array}{c}
-\infty, \text { if } d C_{t}^{0}<d \eta_{t} \\
d C_{t}+d C_{t}^{H}, \text { if } d C_{t}^{0} \geq d \eta_{t}
\end{array},\right.
$$

where $\left\{C_{t}^{0}\right\},\left\{C_{t}\right\}$ and $\left\{C_{t}^{H}\right\}$ denote cumulative flows of the necessary, luxury and housing consumption. ${ }^{6}$

We assume that housing and luxury consumption are perfect substitutes. In other words, housing is a part of luxury consumption. This assumption can be justified by the fact that most US households tend to buy houses by far exceeding their minimum housing needs. The primary difference between luxury consumption

\footnotetext{
${ }^{5}$ Without loss of generality, we can think about the lender as a group of investors who maximize their combined payoff from the relationship with the borrower. How the investors divide proceeds among themselves is not relevant for the purpose of designing an optimal contract between the borrower and the investors.

${ }^{6}$ This specification is similar in flavor to the one used by Ait-Sahalia, Parker and Yogo (2004), who propose a partial resolution of the equity premium puzzle by distinguishing between the consumption of basic goods and that of luxury goods. In their model, households are much more risk averse with respect to the consumption of basic goods, of which a certain amount is required in every period, which is consistent with the subsistence aspect of basic goods and the discretionary aspect of luxuries.
} 
and housing is that luxury consumption can be adjusted instantaneously, while housing consumption is very rigid. We assume that housing consumption remains constant as long as the borrower stays in the same house. $^{7}$

The borrower must use his income to first cover the necessary expenses $\eta_{t}$ before spending on luxury consumption. Let $\bar{Y}_{t} \geq 0$ denote the borrower's total income up to time $t$. We will focus on the borrower's "excess" income $Y_{t} \equiv \bar{Y}_{t}-\eta_{t}$, which represents a better measure of the borrower's ability to pay for a house than the total income. From now on, we will refer to $Y_{t}$ and $C_{t}$ simply as the borrower's income and the borrower's consumption.

The borrower values stochastic cumulative consumption flows $\left\{C_{t}\right\}$ and $\left\{C_{t}^{H}\right\}$ as

$$
E\left[\int_{0}^{\infty} e^{-r t}\left(d C_{t}+d C_{t}^{H}\right)\right]
$$

A standard Brownian motion $Z=\left\{Z_{t}, \mathcal{F}_{1, t} ; 0 \leq t<\infty\right\}$ on $\left(\Omega_{1}, \mathcal{F}_{1}, m_{1}\right)$ drives the borrower's income process, where $\left\{\mathcal{F}_{1, t} ; 0 \leq t<\infty\right\}$ is an augmented filtration generated by the Brownian motion. The borrower's income up to time $t$, denoted by $Y_{t}$, evolves according to

$$
d Y_{t}=\mu d t+\sigma d Z_{t}
$$

where $\mu$ is the drift of the borrower's disposable income and $\sigma$ is the sensitivity of the borrower's income to its Brownian motion component. We assume that the lender knows $\mu$ and $\sigma$, but does not know the realizations of the borrower's excess income shocks $Z_{t}$, so the borrower has the ability to misrepresent his income. Thus, realizations of the borrower's income are not contractible. These assumptions are motivated by the observation that lenders use a variety of methods ${ }^{8}$ to determine a type of the borrower (represented here by $(\mu, \sigma)$ pair) before the loan is approved, but henceforth do not condition the terms of the contract on the realizations of the borrower's income, likely because the borrower's necessary spending shocks and possibly his total income as well are too costly or impossible to monitor.

The borrower is allowed to maintain a private savings account. The private savings account balance $S$ grows at the interest rate $\rho$, where $\rho \leq r$. The borrower must maintain a non-negative balance in his account.

The borrower wants to buy a home at date $t=0$. Home ownership would generate him the public and deterministic utility stream $\frac{d C_{t}^{H}}{d t}=\theta$. The price $P_{0}$ of the home is greater than the borrower's initial wealth $Y_{0}$, i.e., $0 \leq Y_{0}<P_{0} .{ }^{9}$ Thus, the borrower must obtain funds from the lender to finance the house purchase.

\footnotetext{
${ }^{7}$ For simplicity, we do not consider a possibility that the borrower can make modifications that can either increase or decrease the quality of the house.

${ }^{8}$ Such as credit score, demographic variables and so on.

${ }^{9}$ The price $P_{0}$ is considered as a macroeconomic variable, which is not affected by actions of the borrower and the lender. It
} 
We assume that the borrower and the lender are sufficiently small so that their actions have no effect on macroeconomic variables such as the market interest rate. ${ }^{10}$

The housing market is expected to go through two phases. The initial phase, housing boom, is characterized by fast housing appreciation. Housing slump is the absorbing state, characterized by a housing market recession and price stabilization. Let the process $\left\{N_{t}\right\}$ denote the phase of the housing market in the period $t$ :

$$
\begin{gathered}
N_{0}=0, \\
P\left[N_{t+s}=0 \text { for all } s \in[t, t+\Delta) \mid N_{t}=0\right]=e^{-\delta \Delta}, \\
P\left[N_{t+s}=1 \text { for all } s \in[t, t+\Delta) \mid N_{t}=0\right]=1-e^{-\delta \Delta}, \\
P\left[N_{t+s}=0 \text { for all } s \in[t, t+\Delta) \mid N_{t}=1\right]=0 .
\end{gathered}
$$

where $N_{t}=0$ means the housing boom continues in period $t$, and $N_{t}=1$ means the housing slump phase in period $t$. Formally, the process $N=\left\{N_{t}, \mathcal{F}_{2, t} ; 0 \leq t<\infty\right\}$ is a standard compound Poisson process with an intensity $\delta\left(N_{t}\right)$ on a probability space $\left(\Omega_{2}, \mathcal{F}_{2}, m_{2}\right)$, such that $N_{0}=0$ and

$$
\delta\left(N_{t}\right)=\left\{\begin{array}{ll}
\delta & \text { if } N_{t} \text { is even } \\
0 & \text { if } N_{t} \text { is odd }
\end{array} .\right.
$$

The stopping time $\tau^{h}=\inf \left\{t \geq 0: N_{t}=1\right\}$ denotes the arrival time of the housing slump phase. The market price of the home grows at the rate $g>0$ per year during the boom, while it remains constant during the slump:

$$
P_{t}=\left\{\begin{array}{ll}
P_{0} e^{g t} & \text { for all } 0 \leq t<\tau^{h} \\
P_{\tau^{h}}(1-\alpha) & \text { for all } t \geq \tau^{h}
\end{array},\right.
$$

where $\alpha \in[0,1]$ measures the extent of house price depreciation.

Before purchase of the house, the borrower and the lender sign a contract that will govern their relationship after the purchase is made. The contract obligates the borrow to report his income realizations to the lender. Conditional on the history of house prices and the borrower's income reports, the contract specifies transfers between the borrower and the lender and the circumstances under which the lender repossesses the home and the circumstances under which the borrower becomes a full homeowner.

is reasonable to expect that the home price $P_{0}$ is increasing in its utility $\theta$, and the borrower optimizes over the set of available $\left(\theta, P_{0}\right)$ pairs. This optimization is not considered in the paper. This clearly does not lead to a loss of generality, since our analysis applies to any $\left(\theta, P_{0}\right)$ pair.

${ }^{10}$ In a general equilibrium framework, actions of mortgage lenders and homebuyers on the aggregate level can affect macroeconomic variables. However, as long as the economic agents on the individual level have no market power, they should regard macroeconomic variables as exogenous in equilibrium. 


\section{Default Option}

If the borrower violates the terms of the contract or defaults at time $t$, he loses the home and receives his reservation value equal to $A$, which for simplicity we assume to be equal to the expected present value of

the borrower's future income, $\frac{\mu}{r}$. We assume $\mu \geq \theta$ and so $A \geq \frac{\theta}{r}$. The lender sells the repossessed house at a foreclosure auction and receives the payoff $L_{t}=(1-l) P_{t}$, where $l \in(0,1)$ measures the liquidation costs.

\section{Option to Sale}

In each period $t$, the borrower can put the home on the market. If he does so, the probability of finding a buyer at time $t$ equals $\lambda\left(N_{t}\right)$. For simplicity, we assume that the home can be sold immediately during the boom $\lambda(0)=1$, while it is impossible to find a buyer during the slump $\lambda(1)=0$. The house sale generates $P_{t}$. The selling is more efficient than liquidation (as $l<1$ ).

Definition 1 Let $v_{t}$ be the value of full homeownership at time $t$ (e.g., the borrower's continuation utility at time $t$ provided the borrower has no debt). If the housing market is in the boom phase we set $v_{t}=v_{t}^{0}$ and if the housing market is in the slump phase $v_{t}=v^{1}=\frac{\mu+\theta}{r}$.

We note that as the housing slump is an absorbing state, the continuation utility of the borrower who has no debt in the slump phase does not depend on $t$.

The sale of the home is not contractible. The borrower puts the home on the market at the time when it maximizes his expected payoff. We assume that the borrower has to pay the outstanding balance $B_{t}$ of the loan to the lender after he sells the house.

As we will verify in Section 5 , the outstanding balance $B_{t}$ is related to the borrower's continuation utility $a_{t}$ under the optimal contract as follows:

$$
B_{t}=v_{t}-a_{t}
$$

where we remember that $v_{t}$ is the (first-best) value of full homeownership at time $t$. In the boom phase of the housing market we have $v_{t}=v_{t}^{0}$. Thus, after the house sale the borrower's continuation payoff is given by

$$
A_{t}^{S}\left(a_{t}\right)=A+P_{t}-\left(v_{t}^{0}-a_{t}\right),
$$

while the lender receives

$$
L_{t}^{S}\left(a_{t}\right)=v_{t}^{0}-a_{t} .
$$

Note that the borrower will want to sell whenever

$$
A_{t}^{S}\left(a_{t}\right) \geq a_{t},
$$


which is equivalent to

$$
A+P_{t} \geq v_{t}^{0}
$$

The optimal selling time determined by equation (2) does not depend on the outstanding balance or the continuation utility of the borrower. This is because the outstanding balance is linear in the borrower's continuation utility, and they cancel each other out. The optimal selling time also does not depend on the liquidation value $L_{t}$ of the home. This is due to the fact that the borrower does not take into account dead-weight costs associated with liquidation. Equation (2) simply states that the borrower sells the home whenever the value of his outside option $A$ plus the proceeds from the sale exceed his continuation utility under full homeownership.

Proposition 1 The optimal time for the borrower to sell the home is given by

$$
t_{s}^{*}=\frac{1}{g} \log \left(\frac{\theta}{r\left(1-\frac{g}{r+\delta}\right) P_{0}}\right),
$$

and the value of full homeownership at time $t \leq t_{s}^{*}$ in the boom phase of the housing market is equal to

$$
v_{t}^{0}=v^{1}+\underbrace{e^{-(r+\delta)\left(t_{s}^{*}-t\right)}\left[P_{t_{s}^{*}}-\frac{\theta}{r}\right]}_{\text {value of option to sale at } t} .
$$

Proof In the Appendix.

\section{Full Homeownership}

If the borrower becomes a full homeowner at time $t$ (the borrower repays his debt) the contract is terminated and the borrower receives the value of full homeownership equal to $v_{t}$.

\section{Dynamic Moral Hazard Problem}

At time 0 , the funds needed to purchase the home in the amount of $P_{0}-Y_{0}$ are transferred from the lender to the borrower. An allocation, $\left(\tau^{f}, \tau^{d}, I\right)$, specifies a time at which the borrower becomes a full homeowner, $\tau^{f}$, a default time, $\tau^{d}$, and transfers between the lender and the borrower, all of which are based on the borrower's report of his income and the realized house price process. Let $(\Omega, \mathcal{F}, m):=\left(\Omega_{1} \times \Omega_{2}, \mathcal{F}_{1} \times \mathcal{F}_{2}, m_{1} \times m_{2}\right)$ be the product space of $\left(\Omega_{1}, \mathcal{F}_{1}, m_{1}\right)$ and $\left(\Omega_{2}, \mathcal{F}_{2}, m_{2}\right)$. Let $\hat{Y}=\left\{\hat{Y}_{t}: t \geq 0\right\}$ be the borrower's report of his income, where $\hat{Y}$ is $(Y, P)$-measurable $\left(\mathcal{F}_{t}\right.$-measurable). The allocation transfers the reported amount, $\hat{Y}_{t}$, from the borrower to the lender, and $I_{t}(\hat{Y}, P)$ from the lender to the borrower. Below we formally define an allocation. 
Definition 2 An allocation $\xi=\left(\tau^{f}, \tau^{d}, I\right)$ specifies a time at which the borrower becomes a full homeowner $\tau^{f}$, a default time $\tau^{d}$, and transfers from the lender to the borrower $I=\left\{I_{t}: 0 \leq t \leq \tau\right\}$, that are based on $\hat{Y}$ and $P(N)$. Formally, $\tau^{f}$ and $\tau^{d}$ are $(\hat{Y}, P)$-measurable stopping times, and $I$ is a $(\hat{Y}, P)$-measurable continuous-time process, such that the process

$$
E\left[\int_{0}^{\min \left(\tau^{f}, \tau^{d}\right)} e^{-r s} d I_{s} \mid \mathcal{F}_{t}\right]
$$

is square-integrable for $0 \leq t \leq \min \left(\tau^{f}, \tau^{d}\right)$ and $\hat{Y}=Y$.

Definition 3 Let $\tau=\min \left(\tau_{s}^{*}, \tau^{f}, \tau^{d}\right)$, be the expected time of termination of the relationship due to sale (which happens at $t_{s}^{*}$ provided that house boom last until $s$ ), full homeownership, or default, respectively, implied by the allocation $\left(\tau^{f}, \tau^{d}, I\right)$.

The borrower can misreport his income. Consequently, under the allocation $\xi$, up to time $t \leq \tau$, the borrower receives a total flow of income equal to

$$
\underbrace{\left(d Y_{t}-d \hat{Y}_{t}\right)}_{\text {misreporting }}+d I_{t}
$$

and his private savings account balance, $S$, grows according to

$$
d S_{t}=\rho S_{t} d t+\left(d Y_{t}-d \hat{Y}_{t}\right)+d I_{t}-d C_{t}
$$

where $d C_{t}$ is the borrower's consumption at time $t$, which must be non-negative. We recall that $\rho \leq r$.

In response to an allocation $\xi=\left(\tau^{f}, \tau^{d}, I\right)$, the borrower chooses a feasible strategy that consists of his consumption choice, the report of his income, and the selling time in order to maximize his expected utility. Below we formally define the feasible strategy of the borrower.

Definition 4 Given an allocation $\zeta=\left(\tau^{f}, \tau^{d}, I\right)$, a feasible strategy for the borrower is a pair $(C, \hat{Y})$ such that

(i) $\hat{Y}$ is a continuous-time process adapted to $(Y, P)$,

(ii) $C$ is a nondecreasing continuous-time process adapted to $(Y, P)$,

(iii) the savings process defined by (4) stays non-negative.

We haven't included explicitly the borrower's selling decision in the definition of his strategy. As we discussed in Section 2 the optimal selling time is determined by equation (2). Equation (2) simply states 
that it is optimal for the borrower to sell the home whenever the value of his outside option $A$ plus the proceeds from the sale exceed his continuation utility under full homeownership (which happens at $t_{s}^{*}$ provided that house boom last until $s$ ).

The borrower's strategy is incentive compatible if it maximizes his lifetime expected utility in the class of all feasible strategies given an allocation $\zeta=\left(\tau^{f}, \tau^{d}, I\right)$. As a result, we have the following definition.

Definition 5 Given an allocation $\zeta=\left(\tau^{f}, \tau^{d}, I\right)$, the borrower's strategy $(C, \hat{Y})$ is incentive compatible if

(i) given an allocation $\zeta$, the borrower's strategy $(C, \hat{Y})$ is feasible,

(ii) given an allocation $\zeta$, the borrower's strategy $(C, \hat{Y})$ provides him with the highest expected utility among all feasible strategies, that is

$$
\begin{aligned}
& E\left[\int_{0}^{\tau} e^{-r t}\left(d C_{t}+\theta d t\right)+e^{-r \tau}\left(1_{\tau=\tau_{s}^{*}} A_{\tau}^{S}+1_{\tau=\tau^{f}} v_{\tau}+1_{\tau=\tau^{d}} A\right) \mid \mathcal{F}_{0}\right] \geq \\
& E\left[\int_{0}^{\tau} e^{-r t}\left(d C_{t}^{\prime}+\theta d t\right)+e^{-r \tau}\left(1_{\tau=\tau_{s}^{*}} A_{\tau}^{S}+1_{\tau=\tau^{f}} v_{\tau}+1_{\tau=\tau^{d}} A\right) \mid \mathcal{F}_{0}\right]
\end{aligned}
$$

for all the borrower's feasible strategies $\left(C^{\prime}, \hat{Y}^{\prime}\right)$, given an allocation $\zeta$.

The above definition does not explicitly include the participation constraint imposing the condition that the borrower's utility from the continuation of the allocation should be at least as large as the borrower's outside option, $A$, which he can receive at any time by quitting. As the borrower can always under-report and steal at rate $r A$ until a termination time, any incentive compatible strategy would yield the borrower utility of at least $A$.

The above definition of an incentive compatible strategy allows us to define the incentive compatible allocation as follows.

Definition 6 An incentive compatible allocation is an allocation $\zeta=\left(\tau^{f}, \tau^{d}, I\right)$, together with the recommendation to the borrower, $(C, \hat{Y})$, where $(C, \hat{Y})$ is a borrower's incentive compatible strategy given an allocation $\zeta$.

The allocation is optimal if it provides the borrower with his initial expected utility $a_{0}$ and maximizes the expected profit of the lender in the class of all allocations that are incentive compatible. Below we provide a formal definition of the optimal allocation. 
Definition 7 Given the continuation utility to the borrower, $a_{0}$, an allocation $\zeta=\left(\tau^{* f}, \tau^{* d}, I^{*}\right)$, together with a recommendation to the borrower $\left(C^{*}, \hat{Y}^{*}\right)$ is optimal if it maximizes the lender's expected utility:

$$
E\left[\int_{0}^{\tau} e^{-r t}\left(d \hat{Y}_{t}-d I_{t}\right)+e^{-r \tau}\left(1_{\tau=\tau_{s}^{*}} L_{\tau}^{S}+1_{\tau=\tau^{d}} L_{\tau}\right) \mid \mathcal{F}_{0}\right]
$$

in the class of all incentive-compatible allocations that satisfy the following promise keeping constraint:

$$
a_{0}=E\left[\int_{0}^{\tau} e^{-r t}\left(d C_{t}+\theta d t\right)+e^{-r \tau}\left(1_{\tau=\tau_{s}^{*}} A_{\tau}^{S}+1_{\tau=\tau^{f}} v_{\tau}+1_{\tau=\tau^{d}} A\right) \mid \mathcal{F}_{0}\right]
$$

We note that maximizing the lender's expected utility is equivalent to maximizing the lender's profit, which equals the lender's expected utility less the loan amount to the borrower $\left[P_{0}-Y_{0}\right]$, which we take as given.

In the following lemma, we show that searching for optimal allocations, we can restrict our attention to allocations in which truth-telling and zero savings are incentive compatible.

Lemma 1 There exists an optimal allocation in which the borrower chooses to tell the truth and maintains zero savings.

Proof In the Appendix.

The intuition for this result is straightforward. The first part of the result is due to the direct-revelation principle. The second part follows from the fact that it is weakly inefficient for the borrower to save on his private account $(\rho \leq r)$ as any such allocation can be improved by having the lender save and make direct transfers to the borrower. Therefore, we can look for an optimal allocation in which truth-telling and zero savings are incentive compatible.

\section{Derivation of the Optimal Allocation}

In this subsection, we formulate recursively the dynamic moral hazard problem and determine the optimal allocation. First, we consider a problem in which the borrower is not allowed to save. We determine the optimal allocation ${ }^{11}$ in this environment, achieving this in two steps. First, we present and explain the optimal allocation after the house price slump occurred. Next, given the post-slump value function, we derive the optimal allocation in the boom environment.

We know from Lemma 1 that it is sufficient to look for optimal allocations in which the borrower reports truthfully and maintains zero savings, and so the optimal allocation of the problem with no private savings,

\footnotetext{
${ }^{11}$ This is the allocation satisfying the properties of Definition 7 and the additional constraint that $S=0$.
} 
for a given continuation utility to the borrower, yields to the lender at least as much utility as the optimal allocation of the problem when the borrower is allowed to privately save. We will conclude by showing that the optimal allocation of the problem with no private savings is fully incentive compatible, even when the borrower can maintain undisclosed savings, justifying our approach.

Methodologically, our approach is based on continuous-time techniques used by DeMarzo and Sannikov (2006) and extended to a setting with Lévy processes by Piskorski and Tchistyi (2007).

\subsection{The Optimal Allocation without Hidden Savings}

Consider for a moment the dynamic moral hazard problem in which the borrower is not allowed to save. First, we will find a convenient state space for the recursive representation of this problem. For this purpose, we define the borrower's total expected utility received under the allocation $\xi=\left(\tau^{f}, \tau^{d}, I\right)$ conditional on his information at time $t$, from transfers and termination utility, if he tells the truth and follows the optimal selling rule:

$$
V_{t}=E\left[\int_{0}^{\tau} e^{-r s}\left[d I_{s}+\theta d s\right]+e^{-r \tau}\left(1_{\tau=\tau_{s}^{*}} A_{\tau}^{S}+1_{\tau=\tau^{f}} v_{\tau}+1_{\tau=\tau^{d}} A\right) \mid \mathcal{F}_{t}\right]
$$

Lemma 2 The process $V=\left\{V_{t}, \mathcal{F}_{t} ; 0 \leq t<\tau\right\}$ is a square-integrable $\mathcal{F}_{t}$-martingale.

Proof follows directly from the definition of process $V$ and the fact that this process is square-integrable, which is implied by Definition 2 .

Below is a convenient representation of the borrower's total expected utility received under the allocation $\xi=\left(\tau^{f}, \tau^{d}, I\right)$ conditional on his information at time $t$, from transfers and termination utility, if he tells the truth. Let $M=\left\{M_{t}=N_{t}-t \delta\left(N_{t}\right), \mathcal{F}_{1, t} ; 0 \leq t<\infty\right\}$ be a compensated compound Poisson process.

Proposition 2 There exists $\mathcal{F}_{t}$-predictable processes $(\beta, \psi)=\left\{\left(\beta_{t}, \psi_{t}\right) ; 0 \leq t \leq \tau\right\}$ such that

$$
\begin{aligned}
V_{t}= & V_{0}+\int_{0}^{t} e^{-r s} \beta_{s} d Z_{s}+\int_{0}^{t} e^{-r s} \psi_{s} d M_{s}= \\
& V_{0}+\int_{0}^{t} e^{-r s} \beta_{s} \underbrace{\left(\frac{d Y_{s}-\mu d s}{\sigma}\right)}_{d Z_{s}}+\int_{0}^{t} e^{-r s} \psi_{s}\left(d N_{s}-\delta\left(N_{s}\right) d s\right) .
\end{aligned}
$$

Proof We note that the couple $(Z, N)$ is a Brownian-Poisson process, and it is an independent increment process, which is a Lévy processes, on the space $(\Omega, \mathcal{F}, m)$. Then, Theorem III.4.34 in Jacod and Shiryaev (2003) gives us the above martingale representation for a square-integrable martingale adapted to $\mathcal{F}_{t}$ taking values in a finite dimensional space (the process $V$ ).

According to the martingale representation (5), the total expected utility of the borrower under the allocation $\xi$, truth telling, and optimal option execution time conditional on his information at time $t$ equals 
its unconditional expectation plus two terms that represent the accumulated effect on the total utility of, respectively, the income uncertainty revealed up to time $t$ (Brownian motion part), and the house price uncertainty that has been revealed up to time $t$ (compensated compound Poisson part).

According to Proposition 2, when the borrower reports truthfully, his total expected utility under the allocation $\xi$ conditional on the termination time $\tau$ equals

$$
V_{\tau}=V_{0}+\int_{0}^{\tau} e^{-r s} \beta_{s}\left(\frac{d Y_{s}-\mu d s}{\sigma}\right)+\int_{0}^{\tau} e^{-r s} \psi_{s} d M_{s}
$$

As $I$ and $\left(\tau^{f}, \tau^{d}\right)$ depend exclusively on the borrower's report $\hat{Y}$ and the public house price process $P$, when the borrower reports $\hat{Y}$, by (5) he gets the expected utility, $a_{0}(\hat{Y})$, which equals

$$
\begin{aligned}
& a_{0}(\hat{Y})=E[V_{0}+\int_{0}^{\tau} e^{-r t} \beta_{t}\left(\frac{d \hat{Y}_{t}-\mu d t}{\sigma}\right)+\int_{0}^{\tau} e^{-r t} \psi_{t} d M_{t}+\underbrace{\int_{0}^{\tau} e^{-r t}\left(d Y_{t}-d \hat{Y}_{t}\right)}_{\text {utility from stealing }} \mid \mathcal{F}_{0}]= \\
& E\left[V_{0}+\int_{0}^{\tau} e^{-r t} \beta_{t}\left(\frac{d Y_{t}-\mu d t}{\sigma}\right)+\int_{0}^{\tau} e^{-r t}\left(1-\frac{\beta_{t}}{\sigma}\right)\left(d Y_{t}-d \hat{Y}_{t}\right)+\int_{0}^{\tau} e^{-r t} \psi_{t} d M_{t} \mid \mathcal{F}_{0}\right] .
\end{aligned}
$$

Note that because the process $(\beta, \psi)=\left\{\left(\beta_{t}, \psi_{t}\right) ; 0 \leq t \leq \tau\right\}$ is $\mathcal{F}_{t}$-predictable, as for any $t \geq 0, s \geq 0$, $E_{0}\left[Z_{t+s}-Z_{t} \mid \mathcal{F}_{0}\right]=E_{0}\left[M_{t+s}-M_{t} \mid \mathcal{F}_{0}\right]=0$, and given that $E\left[V_{0} \mid \mathcal{F}_{0}\right]=V_{0}$, we have that

$$
a_{0}(\hat{Y})=V_{0}+E\left[\int_{0}^{\tau} e^{-r t}\left(1-\frac{\beta_{t}}{\sigma}\right)\left(d Y_{t}-d \hat{Y}_{t}\right) \mid \mathcal{F}_{0}\right]
$$

Representation (7) leads us to the following formulation of incentive compatibility.

Proposition 3 If the borrower cannot save, truth-telling is incentive compatible if and only if $\beta_{t} \geq \sigma$ $(m-$ a.s. $)$ for all $t \leq \tau$.

Proof Immediately follows from (7).

It is important to stress that in providing incentives for truth-telling one can neglect an impact of reporting strategies on the magnitude of the adjustment, $\psi$, in the borrower's continuation utility that occurs when the house price boom ends. It follows from (6) that, though in principle the reporting strategy of the borrower does affect the magnitude of these adjustments, from the perspective of the borrower such adjustments have zero effect on the borrower's expected utility, whatever his reporting strategy. This property considerably simplifies the formulation of incentive compatibility. 
To characterize the optimal allocation recursively, we define the borrower's continuation utility at time $t$ if he tells the truth as

$$
a_{t}=E\left[\int_{t}^{\tau} e^{-r(s-t)}\left[d I_{s}+\theta d s\right]+e^{-r(\tau-t)}\left[1_{\tau=\tau_{s}^{*}} A_{\tau}^{S}+1_{\tau=\tau^{f}} v_{\tau}+1_{\tau=\tau^{d}} A\right] \mid \mathcal{F}_{t}\right] .
$$

Note that for $t \leq \tau$ we have that

$$
V_{t}=\int_{0}^{t} e^{-r s}\left(d I_{s}+\theta d t\right)+e^{-r t} a_{t}
$$

But this, together with (5), implies the following law of motion of the borrower's continuation utility:

$$
d a_{t}=r a_{t} d t-\theta d t-d I_{t}+\beta_{t} d Z_{t}+\psi_{t} d M_{t}=\left(r a_{t}-\theta-\psi_{t} \delta\left(N_{t}\right)\right) d t-d I_{t}+\beta_{t} d Z_{t}+\psi_{t} d N_{t}
$$

Below we discuss informally, using the dynamic programming approach, how to find out the most efficient way to deliver to a borrower any continuation utility $a \geq A$. Proposition 4 and Proposition 5 will formalize our discussion below.

\section{The Optimal Allocation in the House Slump Phase}

Let $b_{1}\left(a, \tau^{h}\right)$ be the highest expected utility of the lender that can be obtained from an incentive compatible allocation that provides the borrower with utility equal to $a$ given that the house price slump started at $\tau^{h}$. To simplify our discussion we assume that the function $b_{1}$ is concave and $C^{2}$ in its first argument. Proposition 4 will establish these arguments formally. Let $b_{1}^{\prime}$ and $b_{1}^{\prime \prime}$ denote, respectively, the first and second derivative of $b_{1}$ with respect to the borrower's continuation utility $a$.

We start by observing that transferring lump-sum $d I$ from the lender to the borrower with continuation utility $a$, moves an allocation to that of the borrower's continuation utility of $a-d I$. The efficiency implies that

$$
b_{1}\left(a, \tau^{h}\right) \geq b_{1}\left(a-d I, \tau^{h}\right)-d I
$$

which shows that for all $a \in[A, \infty)$ the marginal cost of delivering the borrower his continuation utility can never exceed the cost of an immediate transfer in terms of the lender's utility, that is

$$
b_{1}^{\prime}\left(a, \tau^{h}\right) \geq-1 .
$$

Define $\bar{a}_{\tau^{h}}^{1}$ as the lowest value of $a$ such that $b_{1}^{\prime}\left(a, \tau^{h}\right)=-1$.

Lemma 3 For any $\tau^{h} \in\left[0, t_{s}^{*}\right]$, we have that $\bar{\tau}_{\tau^{h}}^{1}=v^{1}=\frac{\mu+\theta}{r}$. 
Proof Since the borrower and lender have the same discount factors there is no loss of efficiency in delaying the transfers to the borrower. However paying early to the borrower is costly as long it affects the likelihood of costly liquidation. As long as $a_{t}<v^{1}$, the borrower cannot be declared a full homeowner as this would be inconsistent with the borrower's continuation utility. But this implies that as long as $a_{t}<v^{1}$, due to incentive compatibility constraint, there is a positive chance of liquidation. Therefore no transfers would be optimal to the borrower in this region as they would lower the borrower's continuation utility and thus increase the likelihood of liquidation. On the other hand, when $a_{t} \geq v^{1}$ the borrower can be declared a full homeowner (with accompanied transfer from the lender of $a_{t}-v^{1}$ ). As there are no gains for the lender (and for the borrower) from delaying full homeownership, we conclude that $\bar{a}_{\tau^{h}}^{1}=v^{1}$.

Then, conditional on a house price boom ending at $\tau^{h}$, we have that $\tau^{f}=\inf \left\{t \geq \tau^{h}: a_{t}=v^{1}\right\}$. Full ownership and the option to terminate keep the borrower's continuation utility between $A$ and $v^{1}$. But this and (8) imply that when $a \in\left[A, v^{1}\right]$, and when the borrower is telling the truth, his continuation utility evolves according to

$$
d a_{t}=\left(r a_{t}-\theta\right) d t+\beta_{t} d Z_{t}
$$

where we use the fact that $d N_{t}=0$ and $\delta\left(N_{t}\right)=0$ for all $t \geq \tau^{h}$.

We next characterize the optimal choice of process $\left(\beta_{t}\right)$, where $\frac{\beta_{t}}{\sigma}$ determines the sensitivity of the borrower's continuation utility with respect to his report. Using Ito's lemma, we find that

$$
d b_{1}\left(a_{t}, \tau^{h}\right)=\left(r a_{t}-\theta\right) b_{1}^{\prime}\left(a_{t}, \tau^{h}\right) d t+\frac{1}{2} \beta_{t}^{2} b_{1}^{\prime \prime}\left(a_{t}, \tau^{h}\right) d t+\beta_{t} b_{1}^{\prime}\left(a_{t}, \tau^{h}\right) d Z_{t} .
$$

Using the above equation, we find that the lender's expected cash flows and the change in the value he assigns to the allocation are given as follows:

$$
E\left[d Y_{t}+d b_{1}\left(a_{t}, \tau^{h}\right) \mid \mathcal{F}_{t}\right]=\left[\mu+\left(\gamma a_{t}-\theta\right) b_{1}^{\prime}\left(a_{t}, \tau^{h}\right)+\frac{1}{2} \beta_{t}^{2} b_{1}^{\prime \prime}\left(a_{t}, \tau^{h}\right)\right] d t
$$

From Proposition 3, we know that if $\beta_{t} \geq \sigma$ for all $t \leq \tau$ then the borrower's best response strategy is to report the truth, that is, $\hat{Y}=Y$. Because at the optimum, at any time $t$, the lender should earn an instantaneous total return equal to the interest rate, $r$, we have the following Bellman equation for the value function of the lender after the house price boom's end at $\tau^{h}$ :

$$
r b_{1}\left(a_{t}, \tau^{h}\right)=\max _{\beta_{t} \geq \sigma}\left[\mu+\left(r a_{t}-\theta\right) b_{1}^{\prime}\left(a_{t}, \tau^{h}\right)+\frac{1}{2} \beta_{t}^{2} b_{1}^{\prime \prime}\left(a_{t}, \tau^{h}\right)\right] .
$$

Given the concavity of the function $b\left(\cdot, \tau^{h}\right)$, setting

$$
\beta_{t}=\sigma
$$


for all $\tau^{h} \leq t \leq \tau$ is optimal.

The lender's value function therefore satisfies the following differential equation

$$
r b_{1}\left(a_{t}, \tau^{h}\right)=\mu+\left(r a_{t}-\theta\right) b_{1}^{\prime}\left(a_{t}, \tau^{h}\right)+\frac{1}{2} \sigma^{2} b_{1}^{\prime \prime}\left(a_{t}, \tau^{h}\right) .
$$

We need some boundary conditions to pin down a solution to this equation. The first boundary condition arises because the relationship must be terminated to hold the borrower's value to $A$, so $b_{1}\left(A, \tau^{h}\right)=L_{\tau^{h}}$. The second boundary condition comes from the fact that the lender should expect no transfers from the borrower once he becomes a homeowner, that is $b_{1}\left(v^{1}, \tau^{h}\right)=0$. Finally we have that $b_{1}^{\prime}\left(v^{1}, \tau^{h}\right)=-1$.

The proposition below formalizes our findings.

Proposition 4 Let $b_{1}\left(., \tau^{h}\right)$ be a function (in a) that solves:

$$
r b_{1}\left(a, \tau^{h}\right)=\mu+(r a-\theta) b_{1}^{\prime}\left(a_{t}, \tau^{h}\right)+\frac{1}{2} \sigma^{2} b_{1}^{\prime \prime}\left(a, \tau^{h}\right),
$$

when $a$ is in the interval $\left[A, v^{1}\right]$, with boundary conditions $b_{1}\left(A, \tau^{h}\right)=L_{\tau^{h}}, b_{1}\left(v^{1}, \tau^{h}\right)=0$, and $b_{1}^{\prime}\left(v^{1}, \tau^{h}\right)=$ -1 .

Then the optimal allocation that delivers to the borrower the value $a_{\tau^{h}}$ given that the housing slump occurred at $\tau^{h}$, takes the following form. If $a_{\tau^{h}} \in\left[A, v^{1}\right], a_{t}$ evolves for $t>\tau^{h}$ as

$$
d a_{t}=\left(r a_{t} d t-\theta d t\right)+\left(d \hat{Y}_{t}-\mu d t\right)
$$

The default occurs at first time $\tau^{d}$ when $a_{t}$ hits $A$. The borrower becomes a homeowner at first time $\tau^{f}$ when $a_{t}$ hits $v^{1}$. The lender's expected utility at any time $t \geq \tau^{h}$ is given by the function $b_{1}\left(a_{t}, \tau^{h}\right)$ defined above, which is strictly concave in $a_{t}$ over $\left[A, v^{1}\right]$.

Proof Directly follows from DeMarzo and Sannikov (2006) and Bias et al. (2007) as the structure of dynamic moral hazard problem after the house slump corresponds to the one studied in these papers.

The evolution of the continuation utility (13) implied by the optimal allocation serves three objectives: promise-keeping, incentives, and efficiency. The first component of (13) accounts for promise-keeping. In order for $a_{t}$ to correctly describe the lender's promise to the borrower, it should grow at the borrower's discount rate, $r$, less the payment, $\theta d t$, which he receives from owning the home, and less the flow of payments, $d I_{t}$, from the lender.

The second term of (13) provides the borrower with incentives to report his true income to the lender. Because of inefficiencies resulting from liquidation, reducing the risk in the borrower's continuation utility lowers the probability that the borrower's expected utility reaches $A$, and thus lowers the probability of costly liquidation. Therefore, it is optimal to make the sensitivity of the borrower's continuation utility with 
respect to its report as small as possible provided that it does not erode his incentives to tell the truth. The minimum volatility of the borrower's continuation utility with respect to his report of income required for truth-telling equals 1 . To understand this, note that under this choice of volatility, underreporting income by one unit would provide the borrower with one additional unit of current utility through increased consumption, but would also reduce the borrower's continuation utility by one unit, so that this volatility provides the borrower with just enough incentives to report a true realization of income. Note that when the borrower reports truthfully, the term $\left(d \hat{Y}_{t}-\mu d t\right)$ is driftless and equals $\sigma d Z_{t}$.

\section{The Optimal Allocation in the House Price Boom}

Let $b_{0}(a, t)$ be the highest expected utility of the lender that can be obtained from an incentive compatible allocation that provides the borrower with utility equal to $a$ given that we have the house price boom at $t$ $\left(t<\tau^{h}\right)$. To simplify our discussion we assume that the function $b$ is concave and $C^{2}$ in its first argument. Proposition 4 will establish these arguments formally. Let $b_{0}^{\prime}$ and $b_{0}^{\prime \prime}$ denote, respectively, the first and the second derivative of $b_{0}$ with respect to the borrower's continuation utility $a$.

We start by observing that transferring lump-sum $d I$ from the lender to the borrower with continuation utility $a_{t}$ moves an allocation to that of the borrower's continuation utility of $a_{t}-d I$. The efficiency implies that

$$
b_{0}(a, t) \geq b_{0}(a-d I, t)-d I
$$

which shows that for all $a \in[A, \infty)$ the marginal cost of delivering the borrower his continuation utility can never exceed the cost of an immediate transfer in terms of the lender's utility, that is

$$
b_{0}^{\prime}(a, t) \geq-1
$$

Define $\bar{a}_{t}^{0}$ as the lowest value of $a$ such that $b_{0}^{\prime}(a, t)=-1$.

Lemma 4 For any $t \in\left[0, \min \left(\tau^{h}, t_{s}^{*}\right)\right)$, we have that $\bar{a}_{t}^{0}=v_{t}^{0}$.

Proof Since the borrower and lender have the same discount factors there is no loss of efficiency in delaying the transfers to the borrower. However paying early to the borrower is costly as long it affects the likelihood of costly liquidation. As long as $a_{t}<v_{t}^{0}$, the borrower cannot be declared a full homeowner as this would be inconsistent with the borrower's continuation utility. But this implies that as long as $a_{t}<v_{t}^{0}$, due to incentive compatibility constraint, there is a positive chance of liquidation. Therefore no transfers would be optimal to the borrower in this region as they would lower the borrower's continuation utility and thus increase the likelihood of liquidation. On the other hand, when $a_{t} \geq v_{t}^{0}$ the borrower can be declared a full homeowner (with accompanied transfer from the lender of $a_{t}-v_{t}^{0}$ ). As there are no gains for the lender (and for the borrower) from delaying full homeownership, we conclude that $\bar{a}_{t}^{0}=v_{t}^{0}$. 
Then, we have that $\tau^{f}=\inf \left\{t \geq 0: a_{t}=v_{t}\right\}$. The full homeownership and the option to terminate keep the borrower's continuation utility between $A$ and $v_{t}$. But this and (8) imply that when $a \in\left[A, v_{t}\right]$, and when the borrower is telling the truth, his continuation utility for $t<\tau^{h}$ evolves according to

$$
d a_{t}=\left(r a_{t}-\theta-\psi_{t} \delta\right) d t+\beta_{t} d Z_{t}+\psi_{t} d N_{t}
$$

where we use the fact that $\delta\left(N_{t}\right)=\delta$ for $t<\tau^{h}$.

We need to characterize the optimal choice of process $\left(\beta_{t}, \psi_{t}\right)$, where $\frac{\beta_{t}}{\sigma}$ determines the sensitivity of the borrower's continuation utility with respect to his report, and $\psi_{t}$ determines the adjustment of the borrower's continuation utility when the house price boom ends. Using Ito's lemma, we find that

$$
\begin{aligned}
d b_{0}\left(a_{t}, t\right)= & \frac{\partial b_{0}\left(a_{t}, t\right)}{\partial t} d t+\left(r a_{t}-\theta-\psi_{t} \delta\right) b_{0}^{\prime}\left(a_{t}, t\right) d t \\
& +\frac{1}{2} \beta_{t}^{2} b_{0}^{\prime \prime}\left(a_{t}, t\right) d t+\beta_{t} b_{0}^{\prime}\left(a_{t}, t\right) d Z_{t}+\left[b_{1}\left(a_{t}+\psi_{t}, t\right)-b_{0}\left(a_{t}, t\right)\right] d N_{t} .
\end{aligned}
$$

Using the above equation, we find that the lender's expected cash flows and the change in the value he assigns to the allocation are given as follows:

$$
\begin{gathered}
E\left[d Y_{t}+d b_{0}\left(a_{t}, t\right) \mid \mathcal{F}_{t}\right]= \\
{\left[\frac{\partial b_{0}\left(a_{t}, t\right)}{\partial t}+\mu+\left(r a_{t}-\theta-\psi_{t} \delta\right) b_{0}^{\prime}\left(a_{t}, t\right)+\frac{1}{2} \beta_{t}^{2} b_{0}^{\prime \prime}\left(a_{t}, t\right)+\delta\left(b_{1}\left(a_{t}+\psi_{t}, t\right)-b_{0}\left(a_{t}, t\right)\right)\right] d t .}
\end{gathered}
$$

From Proposition 3, we know that if $\beta_{t} \geq \sigma$ for all $t \leq \tau$ then the borrower's best response strategy is to report the truth, that is, $\hat{Y}=Y$. Because at the optimum, at any time $t$, the lender should earn an instantaneous total return equal to the interest rate, $r$, we have the following Bellman equation for the value function of the lender

$$
\begin{gathered}
r b_{0}\left(a_{t}, t\right)= \\
\max _{\beta_{t} \geq \sigma, \psi_{t} \geq A-a_{t}}\left[\frac{\partial b_{0}\left(a_{t}, t\right)}{\partial t}+\mu+\left(r a_{t}-\theta-\psi_{t} \delta\right) b_{0}^{\prime}\left(a_{t}, t\right)+\frac{1}{2} \beta_{t}^{2} b_{0}^{\prime \prime}\left(a_{t}, t\right)+\delta\left(b_{1}\left(a_{t}+\psi_{t}, t\right)-b_{0}\left(a_{t}, t\right)\right)\right],
\end{gathered}
$$

where $t \in\left[0, t_{s}^{*}\right]$.

Given the concavity of the function setting

$$
\beta_{t}=\sigma
$$

for all $t \leq \tau$ is optimal. The concavity of the objective function in $\psi_{t}$ in the RHS of the Bellman equation 
(16) also implies that the optimal choice of $\psi_{t}$ is given as a solution to

$$
b_{0}^{\prime}\left(a_{t}, t\right)=b_{1}^{\prime}\left(a_{t}+\psi_{t}, t\right)
$$

provided that $\psi_{t}>A-a_{t}$, and otherwise $\psi_{t}=A-a_{t}$. Note that the optimal jump can be expressed as $\psi\left(a_{t}, t\right)$.

The lender's value function in the house price boom therefore satisfies the following differential equation for $a_{t} \in\left[A, v_{t}^{0}\right]$ :

$$
r b_{0}\left(a_{t}, t\right)=\frac{\partial b_{0}\left(a_{t}, t\right)}{\partial t}+\mu+\left(r a_{t}-\theta-\psi\left(a_{t}, t\right) \delta\right) b_{0}^{\prime}\left(a_{t}, t\right)+\frac{1}{2} \sigma^{2} b_{0}^{\prime \prime}\left(a_{t}, t\right)+\delta\left(b_{1}\left(a_{t}+\psi\left(a_{t}, t\right), t\right)-b_{0}\left(a_{t}, t\right)\right)
$$

with $\psi$ specified above.

We need some boundary conditions to pin down a solution to this equation. The first boundary condition arises because the relationship must be terminated to hold the borrower's value to $A$, so $b_{0}(A, t)=L_{t}$. The second boundary condition comes from the fact that the lender should expect no transfers from the borrower once the borrower becomes a homeowner, that is $b_{0}\left(v_{t}^{0}, t\right)=0$. Moreover $b_{0}^{\prime}\left(v_{t}^{0}, t\right)=-1$. The final boundary reflects the payments to the lender at the selling time, that is $b_{0}\left(a_{t}, t_{s}^{*}\right)=v_{t_{s}^{*}}^{0}-a_{t}$. The proposition below formalizes our findings.

Proposition 5 Let $b_{0}$ be a $C^{2}$ function (in a) that solves:

$$
r b_{0}\left(a_{t}, t\right)=\frac{\partial b_{0}\left(a_{t}, t\right)}{\partial t}+\mu+\left(r a_{t}-\theta-\psi\left(a_{t}, t\right) \delta\right) b_{0}^{\prime}\left(a_{t}, t\right)+\frac{1}{2} \sigma^{2} b_{0}^{\prime \prime}\left(a_{t}, t\right)+\delta\left(b_{1}\left(a_{t}+\psi\left(a_{t}, t\right), t\right)-b_{0}\left(a_{t}, t\right)\right)
$$

when $a$ is in the interval $\left[A, v_{t}^{0}\right]$ with boundary conditions

$$
\begin{aligned}
b_{0}(A, t) & =L_{t}, \\
b_{0}^{\prime}\left(v_{t}^{0}, t\right) & =-1, \\
b_{0}\left(a_{t}, t_{s}^{*}\right) & =v_{t_{s}^{*}}^{0}-a_{t},
\end{aligned}
$$

where

$$
\psi(a, r)=\left\{\begin{array}{l}
\text { is a } C^{1} \text { (in a) solution to } b_{0}^{\prime}(a, t)=b_{1}^{\prime}(a+\psi, t) \text { for all }(a, t) \\
\text { for which the solution is such that } \psi(a, t)>A-a \\
\text { otherwise it is equal to } A-a
\end{array}\right.
$$

Then the optimal allocation that delivers to the borrower the value $a_{0}$ takes the following form. If $a_{0} \in$ 
$\left[A, v_{0}^{0}\right], a_{t}$ evolves as

$$
d a_{t}=\left(r a_{t} d t-\theta d t-d I_{t}\right)+\left(d \hat{Y}_{t}-\mu d t\right)+\psi\left(a_{t}, t\right)\left(d N_{t}-\delta\left(N_{t}\right) d t\right)
$$

The borrower becomes a homeowner at first $t$ time $\tau^{f}$ when $a_{t}$ hits $v_{t}$, The borrower defaults at first $t$ time $\tau^{d}$ when $a_{t}$ hits $A$. The borrower sells a house at time $t_{s}^{*}$, provides that $t_{s}^{*}<\min \left(\tau^{d}, \tau^{h}\right)$. The lender's expected utility at any time $t<\tau^{h}$ is given by the function $b_{0}\left(a_{t}, t\right)$ defined above, which is strictly concave in $a_{t}$ over $\left[A, v_{t}^{0}\right]$. The lender's expected utility at any time $t>\tau^{h}$ for $a_{t} \in\left[A, v^{1}\right]$ is given by the function $b_{1}\left(a_{t}, \tau^{h}\right)$ defined in Proposition 4.

Proof In the Appendix.

The evolution of the continuation utility (21) implied by the optimal allocation serves three objectives: promise-keeping, incentives, and efficiency. As in the equation (13), the first component of (21) accounts for promise-keeping while the second term provides the borrower with incentives to report his true income to the lender.

The last term of (21) captures the effect of the stochastic house price appreciation on the borrower's continuation utility. The optimal adjustments, $\psi$, in the borrower's continuation utility, which are applicable a when house slump occurs, are such that the sensitivity of the lender's expected utility, $b$, with respect to the borrower's continuation utility, $a$, is equalized just before and after an adjustment is made. ${ }^{12}$ This sensitivity represents an instantaneous marginal cost of delivering to the borrower his continuation utility in terms of the lender's utility, and so the efficiency calls for equalizing this cost across the states. We note that these adjustments imply the compensating trend in the borrower's continuation utility, $-\delta\left(N_{t}\right) \psi\left(a_{t}, t\right) d t$, which exactly offsets the expected effect these adjustments have on the borrower's expected utility.

\subsection{The Optimal Allocation with Hidden Savings}

So far, we have characterized the optimal allocation under the assumption that the borrower cannot save. Now we show that, given the optimal allocation of the problem with no hidden savings, the borrower has no incentive to save at the solution, and thus the allocation of Propositions 4-5 is also optimal in the environment where the borrower can privately save.

Proposition 6 Suppose that the process $a_{t} \in\left[A, v_{t}\right]$ solves

$$
d a_{t}=r a_{t} d t-\theta d t-d I_{t}+\left(d \hat{Y}_{t}-\mu d t\right)+\psi_{t} d M_{t}
$$

\footnotetext{
${ }^{12}$ Provided that the solution to (17) is interior.
} 
until stopping time $\tau=\min \left(\tau^{f}, \tau^{d}, \tau_{s}^{*}\right)$, where $\tau^{f}=\inf \left\{t>0: a_{t}=v_{t}\right\}$ and $\tau^{d}=\inf \left\{t>0: a_{t}=A\right\}$, and where $\psi_{t}$ is an $\mathcal{F}_{t}$-predictable process. Then the borrower's expected utility from any feasible strategy in response to an allocation $\left(\tau^{f}, \tau^{d}, I\right)$ is at most $a_{0}$. Moreover, the borrower attains the expected utility $a_{0}$ if the borrower reports truthfully and maintains zero savings.

Proof In the Appendix.

The above proposition shows that the optimal allocation of Proposition 5, remain incentive compatible even if the borrower is allowed to privately save.

\subsection{A Numerical Example}

In this section we illustrate the features of the optimal allocation in a parametrized example. Table 1 shows the parameters of the model.

Table 1. Parameters of the model

\begin{tabular}{cccccccccccc}
\hline \multicolumn{1}{c}{ Borrower's type } & \multicolumn{1}{c}{ Home type } & \multicolumn{4}{c}{ Housing market } & \multicolumn{2}{r}{ Interest rate } \\
\hline$\mu$ & $\sigma$ & $Y_{0}$ & $A$ & $\theta$ & $P_{0}$ & $g$ & $\delta$ & $l$ & $\alpha$ & $r$ \\
\hline 1 & 1 & 0 & 20 & 0.6 & 8 & 0.12 & 0.4 & 0.25 & 0.05 & 0.05 \\
\hline
\end{tabular}

The left hand-side of Figure 1 shows the lender's continuation payoff as a function of the borrower's continuation utility in the boom phase at time zero and the lender's continuation payoff when the boom turns into the slump at time zero. For a given continuation utility to the borrower, the lender's payoff in the boom phase is always greater than it would be in the slump phase. This is because the liquidation value of the home is higher in the boom phase and keeps growing. In addition, the borrower is less likely to default in the boom phase. The full homeownership utility for the borrower is also greater in the boom phase, since it includes the option to sell the home in the future.

The right hand-side of Figure 1 shows the optimal adjustments in the borrower's continuation utility, $\psi_{t}$, applicable if the boom turns into the slump at time $t$ for $t=0$. For $t>0$, function $\psi_{t}$ has a similar profile. For any $t \geq 0$, the adjustment is zero at termination, i.e., $a_{t}=A$, while for the full homeowner, i.e., $a_{t}=v_{t}^{0}$, the adjustment is negative and equal to the lost value of the the option to sell the home $-\left(v_{t}^{0}-v^{1}\right)$. The jump function $\psi_{t}$ is convex for smaller $a$ 's and concave for bigger $a$ 's. Our simulations for different parameters and $t \geq 0$ show that the jump function $\psi_{t}$ always has a form similar to the one on Figure 1 .

The optimal jump $\psi_{t}$ in the borrower's continuation utility triggered by the slump is partially due to the loss of the option to sell the home. The rest of the jump is the outcome of optimal contracting. Figure 2 decompose the jump into these two components. The solid line connecting points $(A, 0)$ and $\left(v_{t}^{0},-\left(v_{t}^{0}-v^{1}\right)\right)$ represents the reduction in the borrower's continuation utility proportional to his stake in the homeownership 

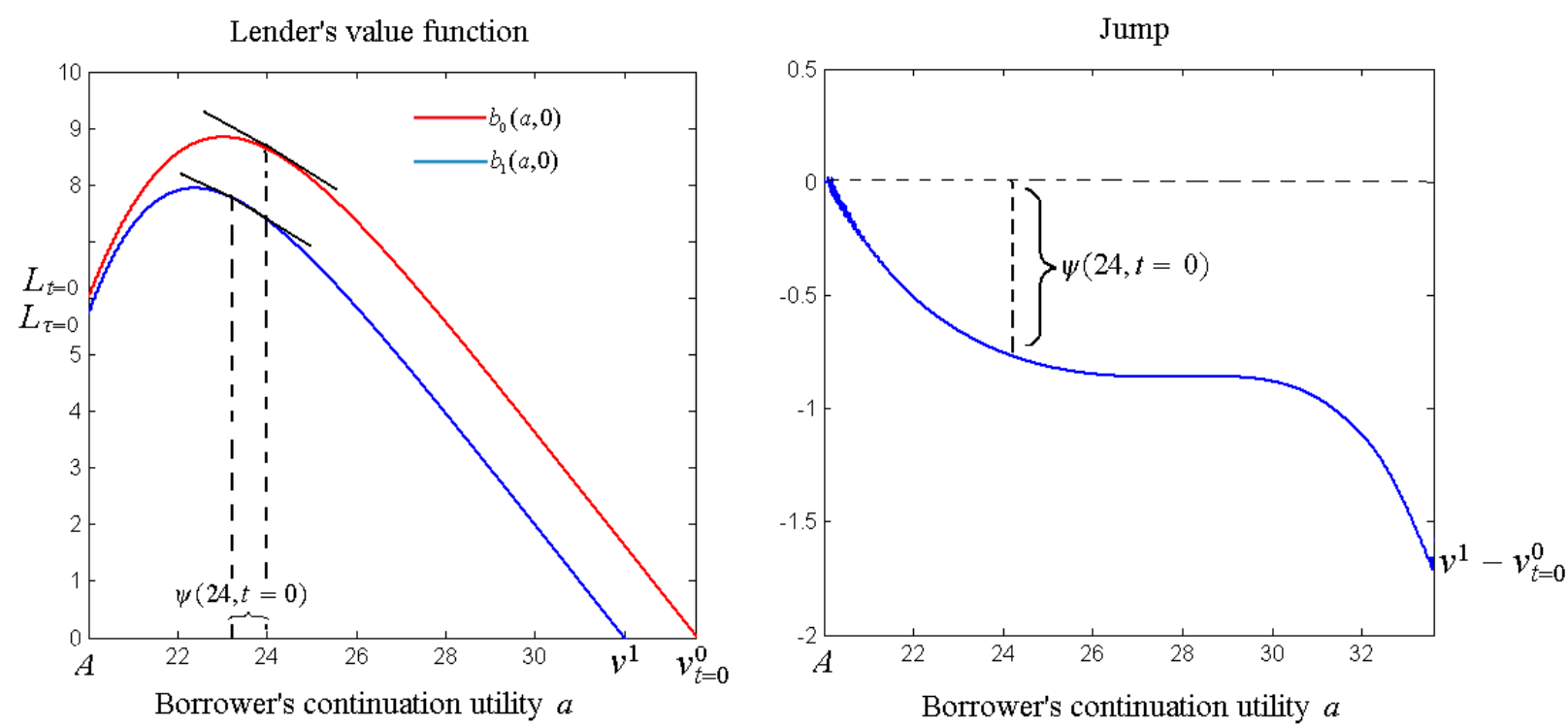

Figure 1: The lender's value function and the optimal adjustments in the borrower's continuation utility.

due to the loss of the option to sell the home. The actual reduction in the continuation utility is bigger for borrowers with low continuation utility (subprime borrowers), and lower for borrowers with high continuation utility (prime borrowers).

According to equation (21), the negative jump $\psi\left(a_{t}, t\right)$ at the beginning of the slump phase translates into a positive continuation utility trend " $-\delta\left(N_{t}\right) \psi\left(a_{t}, t\right) d t$ " in the boom phase. Thus, the subprime borrowers receive preferential treatment, or subsidy, compared to the prime borrowers during the boom phase, while the prime borrowers receive a better treatment, or insurance, in the slump phase.

The subsidy to the subprime borrowers is optimal because it reduces the chances that they default during the boom, which, in turn, maximizes the value of the option to sell the home in the future at a higher price and avoid inefficient bankruptcy procedure. On the other hand, a big negative jump in the continuation utility at the beginning of the slump phase leads to the default clustering among the subprime borrowers. This happens because of the borrower's limited liability and the incentive-compatibility constraints. The insurance of the prime borrowers is explained by the fact that the prime borrowers are not likely to default during the boom, but are more vulnerable during the slump

Since they receive subsidies in the boom phase, bailing out distressed subprime borrowers in the slump phase is not incentive compatible, as it would encourage irresponsible financial behavior. Indeed, borrowers in good standing would prefer not to pay the mortgage in order to qualify for the subsidy in the boom phase and then get help in the slump phase. 


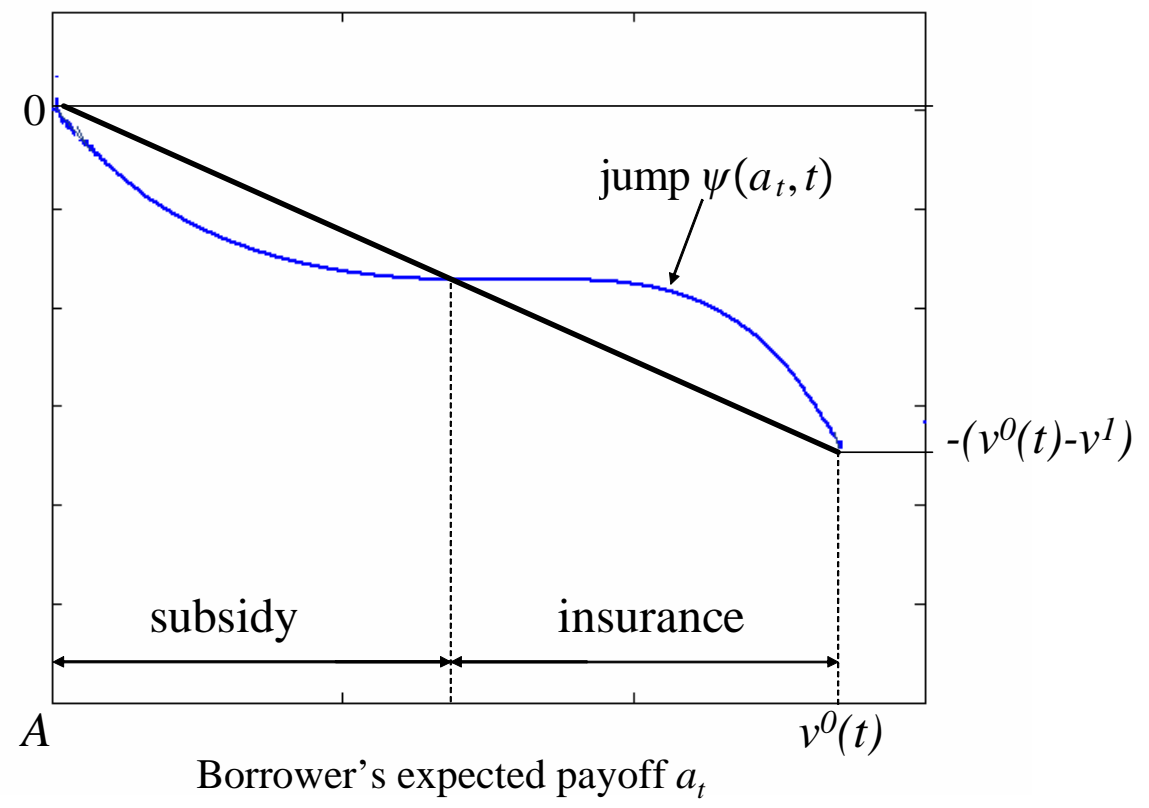

Figure 2: Decomposition of the optimal utility jump $\psi_{t}$

\subsubsection{Utility Gains for the Subprime Borrowers}

First, we show that home appreciation leads to inflow of low income home buyers into the housing market. Then, we demonstrate that the home ownership generates substantial ex-ante utility gains for the subprime borrowers who otherwise would be shut out of the housing market. Our findings provide theoretical evidence that the bubble-like behavior of housing prices can cause rapid growth of the subprime market.

For the other parameters as in Table 1, figure 3 shows the lowest expected income $\mu$, for which the lender breaks even, as a function of the home price growth rate $g$. Faster house appreciation makes it profitable to give loans to borrowers who otherwise would be shut out of the housing market. For example, with the zero home appreciation $(g=0)$, only the borrower with $\mu \geq 0.92$ can take a mortgage and purchase the home. On the other hand, fast home appreciation with $g=12 \%$ makes homeownership possible for the borrower with the mean income $\mu \geq 0.7$.

For the parameters listed in Table 1 (with $g=12 \%$ ), Figure 4 shows the net utility gain $\left(a_{0}-A\right)$ from homeownership as a function of the borrower's mean income $\mu$. Borrowers with $\mu<0.7$ cannot qualify to take the mortgage and purchase the home. However, for borrowers with $\mu>0.7$ buying the home results in substantial expected utility gains.

Note that the gains are significantly bigger than zero even for the borrower with the lowest qualifying income due to incentive reasons. Only when the borrower's expected utility is substantially above his 
Figure 3: The lowest expected income $\mu$, for which the lender breack even, as a function of the home price growth rate $g$.

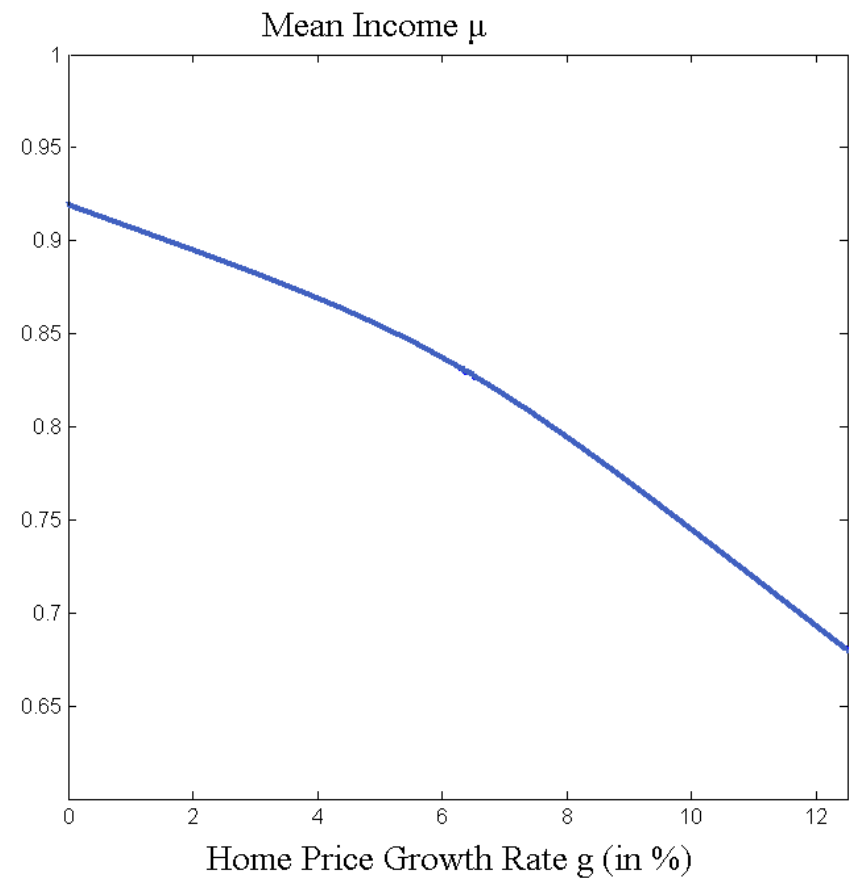

reservation payoff $A$, the borrower has a credible incentive not to default on the mortgage even when his income realization is low. Borrowers who are shut out of the housing market cannot get a loan not only because of their low income but also because of the moral hazard problem.

\section{Implementation}

So far, we have characterized the optimal allocation in terms of the transfers between the borrower and the lender and the timing of liquidation, full ownership and selling. In this section, we show that the optimal allocation can be implemented using financial arrangements that resemble the ones used in the residential mortgage market. In particular, we consider an option mortgage with an adjustable negative amortization limit that has no minimum payment, and comes with a mortgage workout plan. The definition below provides a formal description of this class of mortgage contracts.

Definition 8 An option mortgage with adjustable negative amortization limit consists of:

- Mortgage loan with a time-t negative amortization limit $C_{t}^{L}$,

- Interest rate $\bar{r}_{t}$ charged on the balance, $B_{t}$, of the loan, 


\section{Net Utility Gain from Homeownership}

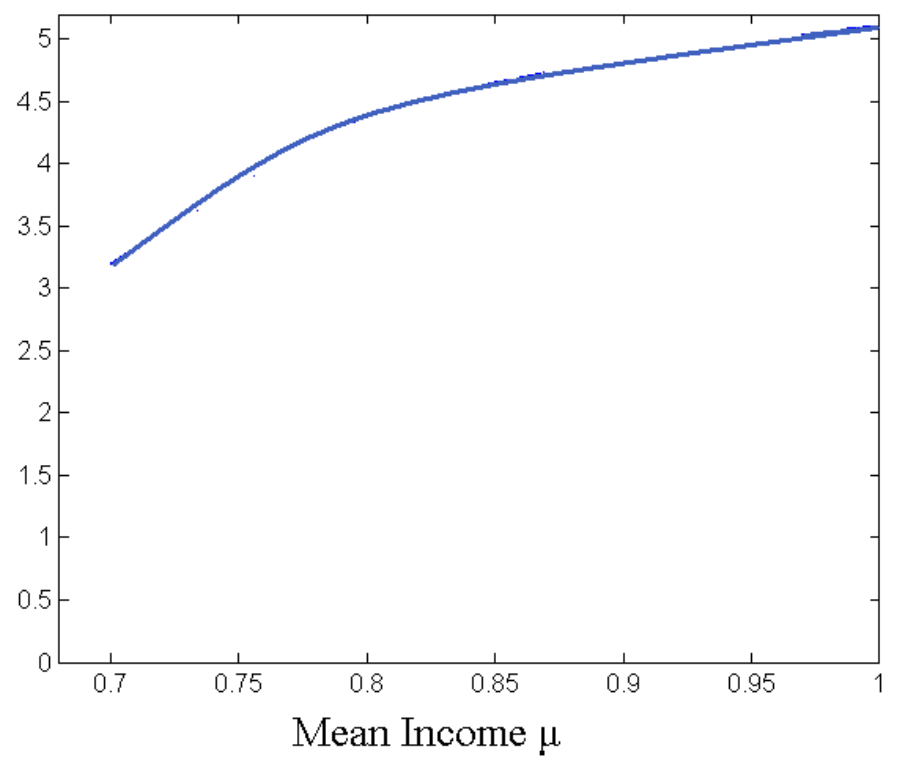

Figure 4: Gains from homeownership

- Subsidy $s_{t}\left(B_{t}\right)$ payable in the boom phase,

- Mortgage insurance premium $i_{t}\left(B_{t}\right)$ payable in the boom phase,

- Initiation fee $F_{0}$ charged by the lender at time zero,

- No minimum interest payment,

- A mortgage modification plan, which includes the balance adjustment $B A_{t}$ and the credit limit adjustment $C A_{t}^{L}$, applicable at the beginning of the housing slump phase.

- If the balance exceeds the negative amortization limit, default occurs, in which case the lender repossesses the home.

Given the definition of the mortgage, the balance in the boom phase evolves according to

$$
d B_{t}=\bar{r}_{t} B_{t} d t-s_{t}\left(B_{t}\right)+i_{t}\left(B_{t}\right)-d \hat{Y}_{t}+d I_{t}+B A_{t} d N_{t}
$$

while the negative amortization limit is increased by $C A_{t}^{L}$ when the housing market switches from the boom to the slump.

Since $b_{0}^{\prime}(a, 0) \geq-1$ for $a \in\left[A, v_{0}^{0}\right]$, it is optimal for the borrower to use all his initial wealth $Y_{0}$ as the downpayment, he has to borrow $P_{0}-Y_{0}$ to buy the home at time zero. However, because of the initiation 
fee $F_{0}$, the initial balance will be $B_{0}=P_{0}-Y_{0}+F_{0}$. We assume that the initiation fee is chosen so that the lender breaks even.

The proposition below shows that the optimal allocation can be implemented with an option mortgage with adjustable negative amortization limit.

Proposition 7 The optimal contract can be implemented using an option mortgage with adjustable negative amortization limit with the following parameters:

$$
\begin{aligned}
C_{t}^{L} & =v_{t}-A, \\
C A_{t}^{L} & =-\left(v_{t}^{0}-v^{1}\right) \\
\bar{r}_{t} & =r+\left(1-N_{t}\right) \delta \frac{v_{t}^{0}-v^{1}}{v_{t}^{0}-A}, \\
s_{t}\left(B_{t}\right) & =\min \left\{0,-\delta\left(\psi_{t}\left(v_{t}^{0}-B_{t}\right)+\frac{v_{t}^{0}-v^{1}}{v_{t}^{0}-A}\left(v_{t}^{0}-A-B_{t}\right)\right)\right\} \\
i_{t}\left(B_{t}\right) & =\min \left\{0, \delta\left(\psi_{t}\left(v_{t}^{0}-B_{t}\right)+\frac{v_{t}^{0}-v^{1}}{v_{t}^{0}-A}\left(v_{t}^{0}-A-B_{t}\right)\right)\right\} \\
B A_{t} & =-\left(v_{t}^{0}-v^{1}\right)-\psi_{t}\left(v_{t}^{0}-B_{t}\right) .
\end{aligned}
$$

The initiation fee $F_{0}$ solves

$$
b_{0}\left(v_{0}^{0}-P_{0}+Y_{0}-F_{0}, 0\right)=P_{0}-Y_{0}
$$

Under the terms of this mortgage, for time $t<\bar{\tau}$, it is optimal for the borrower to use all available income to pay down balance $B_{t}$, as long as $B_{t}>0$, and the borrower's continuation utility $a_{t}$ is equal to

$$
a_{t}=A+\left(C_{t}^{L}-B_{t}\right)=v_{t}-B_{t}
$$

It is optimal to sell the home at time $t_{s}^{*}$ given by equation (3).

Proof In the Appendix.

We will refer to the implementation of the optimal contract given in Proposition 7 as the optimal mortgage. The following remarks highlight the properties of the optimal mortgage.

Remark 1 Credit limit $C_{t}^{L}$, interest rate $\bar{r}_{t}$, and the mortgage modification plan $\left(B A_{t}\right.$ and $\left.C A_{t}^{L}\right)$ do not depend on the amount borrowed at time zero $B_{0}$.

Remark 2 When default happens, the lender receives the liquidation value $L_{t}$ of the home, and the borrower obtains the value A of his outside option.

Remark 3 The interest rate $\bar{r}_{t}$ is increasing with time in the boom phase. Figure 5 shows interest rate $\bar{r}_{t}$ for the parameters listed in Table 1. 
Remark 4 The negative amortization limit is equal to the full ownership value of the home. It can be decomposed into two components:

$$
C_{t}^{L}=v_{t}-A=\left(v^{1}-A\right)+\left(v_{t}-v^{1}\right)
$$

where $\left(v_{t}-v^{1}\right)$ represents the option value to sell the home in the boom phase, and $\left(v^{1}-A\right)$ is the value of the home to the borrower in the slump phase.

Remark 5 The negative amortization limit is increasing with the price of the home in the boom phase. However, at the time when the boom turns to the slump, the negative amortization limit is immediately reduced to $v^{1}-A$ and stays constant. The reduction of the negative amortization limit is equal to the lost value of the option to sell the home $\left(v_{t}^{0}-v^{1}\right)$.

Remark 6 At the time when the borrower sells the home, the negative amortization limit is equal to the price of the home:

$$
C_{t_{s}^{*}}^{L}=v_{t_{s}^{*}}^{0}-A=P_{t_{s}^{*}}
$$

Remark 7 The credit limit increases should not necessarily be automatic. Instead, the borrower may be required to apply for extra credit whenever he experiences financial needs. In this case, $C_{t}^{L}$ can be interpreted as the upper bound on the credit limit at time $t$.

Remark 8 The default clustering happens because of the negative amortization limit reduction. The borrowers whose balance substantially exceeds the new credit limit will default immediately. However, the borrowers whose balance moderately exceeds the new credit limit will be rescued through the balance reduction.

Remark 9 The mortgage modification plan can be interpreted as a loan modification at the time of the crisis imposed by the government regulators.

Remark 10 The optimal mortgage contract takes a very simple form in the slump phase: the home equity line of credits (HELOC) with the fixed interest rate and credit limit. This contract is analogous to the optimal contract in DeMarzo and Sannikov (2007).

Remark 11 The market value of debt $B_{t}$ equals $b_{0}\left(v_{t}^{0}-B_{t}, t\right)$ in the boom phase and $b_{1}\left(v^{1}-B_{t}, \tau^{h}\right)$ in the slump phase.

How does the optimal option adjustable rate mortgage implement the optimal allocation? The debt balance works as a memory device that summarizes all the relevant information regarding the borrower's past income realizations revealed through his payments to the lender. The interest rates charged on the balance, along with the negative amortization limit, are chosen so that equation (29) always holds. This 
Figure 5: Interest rate $\bar{r}_{t}$ as a function of $t$

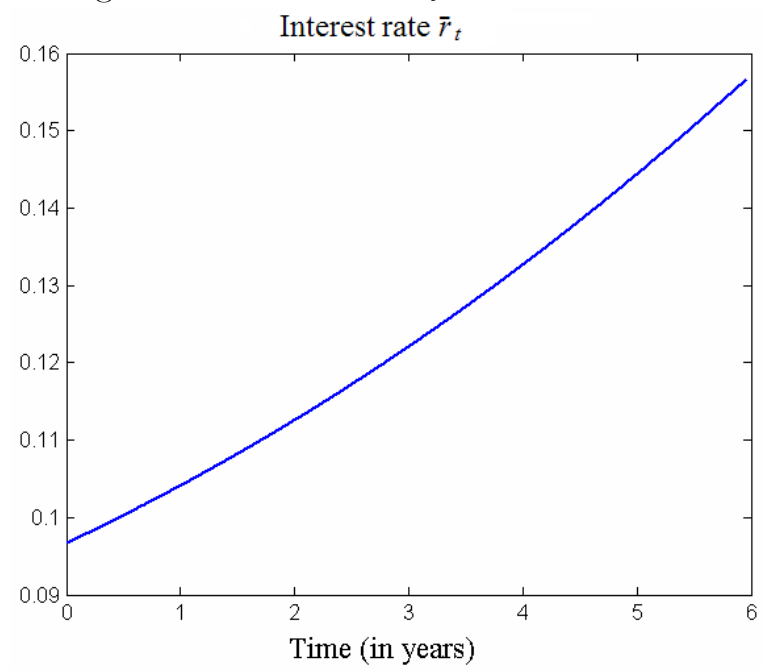

ensures incentive compatibility of the mortgage because, according to equation (29), for every dollar paid to the lender (borrowed from the lender) the borrower's continuation payoff $a_{t}$ goes up (down) by the same amount. For example, at any time $t$ the borrower can consume all his available credit $C_{t}^{L}-B_{t}$ and default immediately. However, equation (29) implies that the payoff from this deviation is exactly equal to his equilibrium payoff $a_{t}$ under the optimal mortgage.

The optimal mortgage provides financial flexibility by allowing the borrower to draw on the credit line, whenever his income is not sufficient to make the interest payment. There is no minimum payment requirement - a low payment from the borrower translates into a higher balance. As a result, the borrower does not need to maintain precautionary savings, because the credit commitments by the lender provide a safety net.

A peculiar feature of the optimal mortgage is that, in the boom phase, the negative amortization limit $C_{t}^{L}$ is greater than the market value of the home $P_{t}$, and is increasing with the price of the home. The borrower with the balance greater than $P_{t}$ nonetheless has utility gains from continuing to pay down the mortgage and keeping the home rather than defaulting or selling the home early. Indeed, if the borrower defaults or sells the home, his continuation utility is equal to his outside option $A$. On the other hand, if the borrower sticks with the mortgage, he will keep the house and enjoy utility flow $\theta$. In addition, if he avoids default in the boom phase, the borrower will sell the home for profit at time $t_{s}^{*}$.

It is also optimal for the lender to allow the borrower to borrow above the value of the home in the boom phase. Of course, if the borrower defaults immediately due to either negative income shocks or the arrival of the slump phase, a higher balance translates into higher losses for the lender. However, by increasing the borrowing limit in the boom phase, the lender minimizes the chances of default due to negative income 
shocks. Avoiding default in the boom phase, in turn, has three positive effects on the value of the mortgage. First, because the home price grows faster than the borrowing limit, default in the future will be less costly for the lender. Second, avoiding default in boom phase increases the chance that the borrower will survive long enough to sell the home at time $t_{s}^{*}$ (at which time $C_{t_{s}^{*}}^{L}=P_{t_{s}^{*}}$ ) and fully repay the balance. A higher balance today translates into a higher payoff for the lender when the borrower sells the home. Third, the borrower can receive positive income shocks, fully repay the balance, and become full homeowner.

\section{Concluding Remarks}

Recent years have seen a rapid growth of the subprime mortgage market followed by the subprime crisis. Because of high default rates among subprime borrowers and big losses among subprime investors accompanied by the crisis in the housing market, subprime mortgages have caused a storm of controversy and criticism. In this paper, we show that many features of subprime lending observed in practice are consistent with rationality of both borrowers and lenders. In particular, preferential treatment of subprime borrowers is optimal during the housing boom, while default clustering among subprime borrowers is optimal during the housing slump. We also find that stochastic house appreciation makes it profitable to give loans to subprime borrowers who otherwise would be shut out of the housing market and that home ownership generates substantial ex-ante utility gains for these borrowers.

In terms of policy implications, our model suggests that bailing out the most distressed subprime borrowers in the slump phase, is not incentive compatible, as it encourages irresponsible financial behavior. On the other hand, it makes sense to help borrowers who were in good standing before the crisis.

Our analysis is based on the assumption of full rationality of borrowers and lenders. Thus, it cannot be applied to a situation with irrational borrowers or lenders. However, policy makers considering banning or imposing strong regulations on subprime lending should justify such actions by presenting evidence of borrowers' or lender's irrationality, rather than simply pointing out to higher default rates among subprime borrowers.

The optimal contracts do not allow borrowers to refinance their mortgages with another lender. Offering this option would increase the borrower's reservation value, which would limit the ability to provide him incentives to repay his debt, resulting in a decrease of efficiency of the contract. Therefore, our results lend support to prepayment penalties on refinancing. Introduction of borrowers' mobility would result in a "soft" prepayment penalty, borrowers could sell their home at anytime without penalty, but if they want to refinance the mortgage, they would pay the prepayment penalty sufficiently large to discourage it.

In this paper, we ignored inflation, which is an important consideration for home buyers choosing between ARMs and FRMs. ${ }^{13}$ However, as long as inflation affects the borrower's income and the liquidation value of

\footnotetext{
${ }^{13}$ See, for example, Campbell and Cocco (2003).
} 
the home equally, it would not change the properties of the optimal mortgage in real terms. We also did not allow for contract renegotiations, because a possibility of renegotiation would lead to a suboptimal contract. In practice, lenders should be able to commit to the terms of a mortgage contract, as the competition among them would drive those who are unable to do so out of the market.

There are a number of research directions one might pursue from here. One of them is to develop a general equilibrium model of the "housing bubble". The findings of this study let us suggest that optimal features of subprime lending can contribute to the "housing bubble". During the housing boom, the inflow of subprime borrowers into the housing market may help sustain house appreciation, possibly driving home prices above the equilibrium level. However, default clustering among subprime borrowers during the housing slump may exacerbate the crisis in the housing market. Thus, the features of subprime lending that are optimal at the individual level may have negative consequences at the aggregate level, since the borrower and the lender do not take into account the potential negative externalities that their optimal contract might impose. 


\section{Appendix}

\section{Proof of Proposition 1}

Let $\Delta$ be the length of the period. The optimal selling time $t_{s}$ under full homeownership conditional on prices growing is the smallest $t$ such that:

$$
P_{t}(1-s)+A \geq e^{-\Delta r}\left[\Delta(\mu+\theta)+e^{-\Delta \delta}\left(e^{\Delta g} P_{t}+A\right)+\left(1-e^{-\Delta \delta}\right)\left(\frac{\Delta(\mu+\theta)}{1-e^{-\Delta r}}\right)\right]
$$

which yields:

$$
e^{\Delta r}\left[P_{t}+A\right] \geq \Delta(\mu+\theta)+e^{-\Delta \delta} e^{\Delta g} P_{t}+e^{-\Delta \delta} A+\left(1-e^{-\Delta \delta}\right)\left(\frac{\Delta(\mu+\theta)}{1-e^{-\Delta r}}\right) .
$$

The above implies that

$$
t_{s}^{*}=\inf \left\{t<\tau:\left(e^{\Delta r}-e^{\Delta(g-\delta)}\right) P_{t}+\left(e^{\Delta r}-e^{-\Delta \delta}\right) A \geq \frac{\left(2-e^{-\Delta r}-e^{-\Delta \delta}\right) \Delta(\mu+\theta)}{1-e^{-\Delta r}}\right\}
$$

that is

$$
t_{s}^{*}=\inf \left\{t<\tau:\left(e^{\Delta r}-e^{\Delta(g-\delta)}-1+e^{\Delta(g-\delta-r)}\right) P_{t}+\left(e^{\Delta r}-e^{-\Delta \delta}\right) \mu \geq\left(2-e^{-\Delta r}-e^{-\Delta \delta}\right) \Delta(\mu+\theta)\right\} .
$$

Taking limit as $\Delta \rightarrow 0$, we obtain:

$$
(r+\delta-g) P_{t_{s}^{*}}+(r+\delta) A=\frac{(r+\delta)(\mu+\theta)}{r} .
$$

As $A=\frac{\mu}{r}$, we have that

$$
P_{t_{s}^{*}}=\frac{\theta}{r\left(1-\frac{g}{r+\delta}\right)} .
$$

This implies that the optimal selling time satisfies

$$
t_{s}^{*}=\frac{1}{g} \log \left(\frac{\theta}{r\left(1-\frac{g}{r+\delta}\right) P_{0}}\right),
$$

provided that the solution exists. Therefore, a sale will occur at $0<t_{s}^{*}<\infty$, conditional on prices growing, iff:

$$
1<\frac{\theta}{r\left(1-\frac{g}{r+\delta}\right) P_{0}}<\infty .
$$


We also note that the value of full homeownership for $0 \leq t<t_{s}$ is given by:

$$
v_{t}^{0}=A+\int_{t}^{t_{s}^{*}} e^{-r(s-t)} \theta d s+e^{-r\left(t_{s}^{*}-t\right)} E_{t}\left[\left(1-N_{t_{s}^{*}}\right) e^{g t_{s}^{*}} P_{0}+N_{t_{s}^{*}} \frac{\theta}{r}\right],
$$

which yields:

$$
v_{t}^{0}=A+\left[1-e^{-(r+\delta)\left(t_{s}^{*}-t\right)}\right] \frac{\theta}{r}+e^{-(r+\delta)\left(t_{s}^{*}-t\right)} e^{g t_{s}^{*}} P_{0} .
$$

We remember that the value of homeownership for any $t \geq \tau^{h}$ is equal to

$$
v^{1}=A+\frac{\theta}{r}=\frac{\mu+\theta}{r} .
$$

Using this we note that for $0 \leq t \leq t_{s}^{*}$ :

$$
v_{t}^{0}=v^{1}+\underbrace{e^{-(r+\delta)\left(t_{s}^{*}-t\right)}\left[P_{t_{s}^{*}}-\frac{\theta}{r}\right]}_{\text {value of option to sale at } t} .
$$

\section{Proof of Lemma 1}

Consider any incentive compatible allocation $\left(\tau^{f}, \tau^{d}, I, C, \hat{Y}\right)$. We prove the lemma by showing the existence of the new incentive-compatible allocation that that has the following properties:

(i) the borrower gets the same expected utility as under the old allocation $\left(\tau^{f}, \tau^{d}, I\right)$,

(ii) the borrower chooses to reveal the cash flows truthfully,

(iii) the borrower maintains zero savings,

(iv) the lender gets the same or greater expected profit as under the old allocation $\left(\tau^{f}, \tau^{d}, I\right)$.

We haven't included explicitly the borrower's selling decision in the definition of his strategy. As we discussed in Section 2 the optimal selling time is determined by equation (2). Equation (2) simply states that it is optimal for the borrower to sell the home whenever the value of his outside option $A$ plus the proceeds from the sale exceed his continuation utility under full homeownership (which happens at $t_{s}^{*}$ ).

Consider the candidate incentive compatible allocation $\left(\tau^{\prime f}, \tau^{\prime d}, I^{\prime}, C, Y\right)$ where

$$
\begin{aligned}
\tau^{\prime f}(Y, P) & =\tau^{f}(\hat{Y}(Y, P), P), \\
\tau^{\prime d}(Y, P) & =\tau^{d}(\hat{Y}(Y, P), P), \\
I^{\prime}(Y, P) & =C(Y, P) .
\end{aligned}
$$


We observe that the borrower's consumption and the termination time under the new allocation and the proposed borrower's response strategy, $(C, Y)$, are the same as under the old allocation, so he earns the same expected utility, which establishes property (i). Also, by construction, the proposed response of the borrower to the allocation $\left(\tau^{\prime f}, \tau^{\prime d}, I^{\prime}\right)$ involves truth-telling and zero savings, which establishes properties (ii) and (iii).

Now we will show that $(C, Y)$ is the borrower's incentive compatible strategy under the allocation $\left(\tau^{\prime f}, \tau^{\prime d}, I^{\prime}\right)$. We note that the strategy $(C, Y)$ yields the same utility to the borrower under the allocation $\left(\tau^{\prime f}, \tau^{\prime d}, I^{\prime}\right)$ as the incentive compatible strategy associated with the allocation $\left(\tau^{f}, \tau^{d}, I\right)$. Therefore, to show that $(C, Y)$ is the borrower's incentive compatible strategy under the allocation $\left(\tau^{\prime f}, \tau^{\prime d}, I^{\prime}\right)$, it is enough to show that if any alternative strategy $\left(C^{\prime}, Y^{\prime}\right)$ is feasible under the allocation $\left(\tau^{\prime f}, \tau^{\prime d}, I^{\prime}\right)$, then $C^{\prime}$ is also feasible under the old allocation $\left(\tau^{f}, \tau^{d}, I\right)$.

It follows that if $C^{\prime}$ is feasible under the new allocation, then the borrower has nonnegative savings if he reports $\hat{Y}\left(Y^{\prime}(Y, P), P\right)$ and consumes $C^{\prime}$ under the old allocation, and thus $C^{\prime}$ is also feasible under the old allocation $\left(\tau^{f}, \tau^{d}, I\right)$. To see this we note that that the borrower's savings at any time $t \leq \min \left(\tau^{\prime f}\left(Y^{\prime}(Y, P), P\right), \tau^{\prime d}\left(Y^{\prime}(Y, P), P\right), t_{s}^{*}\right)=\min \left(\tau^{f}\left(\hat{Y}\left(Y^{\prime}(Y, P), P\right), \tau^{d}\left(\hat{Y}\left(Y^{\prime}(Y, P), P\right), t_{s}^{*}\right)\right.\right.$ under the old allocation $\left(\tau^{f}, \tau^{d}, I\right)$ and the borrower's strategy $\left(C^{\prime}, \hat{Y}\left(Y^{\prime}(Y, P), P\right)\right)$ are equal to

$$
\begin{aligned}
& \underbrace{\int_{0}^{t} e^{\rho(t-s)}\left[d Y_{s}-d \hat{Y}_{s}\left(Y^{\prime}(Y, P), P\right)+d I_{s}\left(\hat{Y}\left(Y^{\prime}(Y, P), P\right)-d C_{s}^{\prime}(Y, P)\right]\right.}= \\
& \text { Savings under the old allocation, the borrower's strategy }\left(C^{\prime}, \hat{Y}\left(Y^{\prime}(Y, P), P\right)\right) \text {, and the realized }(Y, P) \\
& \underbrace{\int_{0}^{t} e^{\rho(t-s)}\left[d Y_{s}^{\prime}(Y, P)-d \hat{Y}_{s}\left(Y^{\prime}(Y, P), P\right)+d I_{s}\left(\hat{Y}\left(Y^{\prime}(Y, P), P\right)-d C_{s}\left(Y^{\prime}(Y, P), P\right)\right]\right.} \\
& (\geq 0) \text { Savings under the old allocation given the borrower's strategy }\left(C, \hat{Y}\left(Y^{\prime}(Y, P), P\right)\right) \text {, and the realized }\left(Y^{\prime}(Y, P), P\right) \\
& \underbrace{+\int_{0}^{t} e^{\rho(t-s)}[d Y_{s}-d Y_{s}^{\prime}(Y, P)+\underbrace{d C_{s}\left(Y^{\prime}(Y, P), P\right)}_{=I^{\prime}\left(Y^{\prime}(Y, P), P\right)}-d C_{s}^{\prime}(Y, P)]} \quad \geq 0 .
\end{aligned}
$$

Finally, to complete the proof, we need to show that under the new allocation $\left(\tau^{\prime f}, \tau^{\prime d}, I^{\prime}\right)$ the lender gets the same or greater expected profit as under the allocation $\left(\tau^{f}, \tau^{d}, I\right)$. Note that under the new allocation the lender does savings for the borrower. As by assumption the lender's interest rate process is always greater or equal from the saving's interest rate available to the borrower (i.e. $r \geq \rho$ ), the lender's expected profit improves by

$$
E_{0}\left[\int_{0}^{\tau} e^{-r t}(r-\rho) S_{t} d t\right] \geq 0
$$


where, $\tau=\min \left(\tau^{\prime f}(Y, P), \tau^{\prime d}(Y, P), t_{s}^{*}\right)=\min \left(\tau^{f}(\hat{Y}(Y), P), \tau^{d}\left(\hat{Y}(\hat{Y}(Y), P), t_{s}^{*}\right)\right.$ which shows (iv).

\section{Proof of Proposition 5}

Let $b_{0}$ be a $C^{2}$ function (in $a$ ) that solves:

$$
r b_{0}(a, t)=\frac{\partial b_{0}(a, t)}{\partial t}+\mu+(r a-\theta-\psi(a, t) \delta) b_{0}^{\prime}(a, t)+\frac{1}{2} \sigma^{2} b_{0}^{\prime \prime}(a, t)+\delta\left(b_{1}(a+\psi(a, t), t)-b_{0}(a, t)\right)
$$

when $a$ is in the interval $\left[A, v^{0}(t)\right]$, and $b_{0}^{\prime}(a, r)=-1$ when $a>v^{0}(t)$, with boundary conditions $b_{0}(A, t)=L_{t}$ and $b_{0}\left(v^{0}(t), t\right)=0$, where

$$
\psi(a, r)=\left\{\begin{array}{l}
\text { is a } \left.C^{1} \text { (in } a\right) \text { solution to } b_{0}^{\prime}(a, t)=b_{1}^{\prime}(a+\psi, t) \text { for all }(a, t) \\
\text { for which the solution is such that } \psi(a, t)>A-a \\
\text { otherwise it is equal to } A-a
\end{array}\right.
$$

First, the concavity of function $b_{0}(\cdot, t)$ can be established as in Piskorski and Tchistyi (2007) using the fact that the function $b_{1}$ is concave (Proposition 4 ).

Now for any incentive compatible allocation $\left(\tau^{f}, \tau^{d}, I, C, Y\right)$ and $t \leq \min \left(\tau^{h}, \tau\right)$ we define:

$$
G_{t}=\int_{0}^{t} e^{-r t}\left(d Y_{s}-d I_{s}\right)+e^{-r t} b\left(a_{t}, t\right)
$$

where $a_{t}$ evolves according to (8). We note that the process $G$ is such that $G_{t}$ is $\mathcal{F}_{t}$-measurable.

We remember that under an arbitrary incentive compatible allocation, $\left(\tau^{f}, \tau^{d}, I, C, Y\right), a_{t}$ evolves for $t \leq \min \left(\tau^{h}, \tau^{f}, \tau^{d}\right):$

$$
d a_{t}=\left(\gamma a_{t}-\theta-\psi_{t} \delta\right) d t-d I_{t}+\beta_{t} d Z_{t}+\psi_{t} d N_{t}
$$

where $\beta_{t} \geq \sigma m$-a.s. for any $0 \leq t \leq \tau$. From Ito's lemma we get that

$$
\begin{gathered}
d b_{0}\left(a_{t}, t\right)=\frac{\partial b_{0}(a, t)}{\partial t}+\left[\left(\gamma a_{t}-\theta-\psi_{t} \delta\right) b_{0}^{\prime}\left(a_{t}, t\right)+\frac{1}{2} \beta_{t}^{2} b_{0}^{\prime \prime}\left(a_{t}, t\right)\right] d t-b_{0}^{\prime}\left(a_{t}, t\right) d I_{t} \\
+\beta_{t} b_{0}^{\prime}\left(a_{t}, t\right) d Z_{t}+\left[b_{1}\left(a_{t}+\psi_{t}, t\right)-b_{0}\left(a_{t}, t\right)\right] d N_{t}
\end{gathered}
$$

We note that (31) implies

$$
e^{r t} d G_{t}=d Y_{t}-d I_{t}+d b_{0}\left(a_{t}, t\right)-r b_{0}\left(a_{t}, t\right)
$$


Substituting from (32) for $d b_{0}\left(a_{t}, t\right)$ in the above and using $d Y_{t}=\mu d t+\sigma d Z_{t}$ yields

$$
\begin{aligned}
e^{r t} d G_{t}= & \frac{\partial b_{0}(a, t)}{\partial t}+\left[\mu+\left(\gamma a_{t}-\theta-\psi_{t} \delta\right) b_{0}^{\prime}\left(a_{t}, t\right)+\frac{1}{2} \beta_{t}^{2} b_{0}^{\prime \prime}\left(a_{t}, r_{t}\right)-r b_{0}^{\prime}\left(a_{t}, t\right)\right] d t-r b_{0}\left(a_{t}, t\right) \\
& -\left(1+b_{0}^{\prime}\left(a_{t}, t\right)\right) d I_{t}+\left(\sigma+\beta_{t} b_{0}^{\prime}\left(a_{t}, t\right)\right) d Z_{t}+\left[b_{1}\left(a_{t}+\psi_{t}, t\right)-b_{0}\left(a_{t}, t\right)\right] d N_{t}
\end{aligned}
$$

Substituting from (30) for $r b_{0}\left(a_{t}, t\right)$ in the above yields

$$
\begin{aligned}
e^{r t} d G_{t}= & {\left[\frac{1}{2}\left(\beta_{t}^{2}-\sigma^{2}\right) b_{0}^{\prime \prime}\left(a_{t}, t\right)+\delta b_{0}^{\prime}\left(a_{t}, t\right)\left[\psi\left(a_{t}, t\right)-\psi_{t}\right]\right] d t-\left(1+b_{0}^{\prime}\left(a_{t}, t\right)\right) d I_{t} } \\
& +\left(\sigma+\beta_{t} b_{0}^{\prime}\left(a_{t}, t\right)\right) d Z_{t}+\left[b_{1}\left(a_{t}+\psi_{t}, t\right)-b_{1}\left(a_{t}+\psi\left(a_{t}, t\right), t\right)\right] d N_{t}
\end{aligned}
$$

whenever $a \in\left[A, v_{t}^{0}\right]$. From the above we have that for any $0 \leq t<\min \left(\tau^{h}, \tau\right)$ :

$$
\begin{aligned}
e^{r t} d G_{t} \leq & \underbrace{\left[\frac{1}{2}\left(\beta_{t}^{2}-\sigma^{2}\right) b_{0}^{\prime \prime}\left(a_{t}, t\right)\right]}_{\leq 0} d t \underbrace{-\left(1+b_{0}^{\prime}\left(a_{t}, t\right)\right) d I_{t}}_{\leq 0} \\
& +\underbrace{\delta\left(\left[b_{1}\left(a_{t}+\psi_{t}, t\right)-\psi_{t} b_{0}^{\prime}\left(a_{t}, t\right)\right]-\left[b_{1}\left(a_{t}+\psi\left(a_{t}, t\right), t\right)-\psi\left(a_{t}, t\right) b_{0}^{\prime}\left(a_{t}, t\right)\right]\right)}_{\leq 0} d t \\
& +\left(\sigma+\beta_{t} b_{0}^{\prime}\left(a_{t}, t\right)\right) d Z_{t}+\left[b_{1}\left(a_{t}+\psi_{t}, t\right)-b_{1}\left(a_{t}+\psi\left(a_{t}, t\right), t\right)\right] d M_{t},
\end{aligned}
$$

where $d M_{t}=d N_{t}-\delta d t$. The first component of the RHS of the above inequality is less or equal to zero because the function $b_{0}$ is concave and $\beta_{t} \geq \sigma$ for any $t \leq \min \left(\tau^{h}, \tau\right)$. The second component is less or equal to zero because $b_{0}^{\prime} \geq-1$ and $d I_{t} \geq 0$. The third component is less or equal to zero because, by definition, the function $\psi$ is a solution to

$$
\left.\max _{\psi \geq A-a}\left[b_{1}(a+\psi, t)-\psi b_{0}^{\prime}(a, t)\right)\right] .
$$

The condition (33) implies that the process $G$ is an $\mathcal{F}_{t}$-supermartingale up to time $t=\min \left(\tau^{h}, \tau\right)$, where we recall that $Z$ and $M$ are martingales. It will be an $\mathcal{F}_{t}$-martingale if and only if, for $t>0, \beta_{t}=\sigma m$-a.s., $\psi_{t}=\psi\left(a_{t}, t\right)$, and $d I_{t}=0$.

Let

$$
b(a, t)=\left\{\begin{array}{c}
b_{0}(a, t) \quad \text { for } a \in\left[A, v_{t}^{0}\right] \text { and } t<\tau^{h} \\
b_{1}\left(a, \tau^{h}\right) \quad \text { for } a \in\left[A, v^{1}\right] \text { and } t \geq \tau^{h}
\end{array} .\right.
$$

We now evaluate the lender's expected utility for an arbitrary incentive compatible allocation $\left(\tau^{f}, \tau^{d}, I, C, Y\right)$, which equals

$$
E\left[\int_{0}^{\tau} e^{-r s}\left(d Y_{s}-d I_{s}\right)+e^{-r \tau} b\left(a_{\tau}, \tau\right)\right]
$$

We note that for $\tau=\tau_{s}^{*}$ we have that $b\left(a_{\tau}, \tau\right)=v_{t_{s}^{*}}^{0}-a_{t_{s}^{*}}$, for $\tau=\tau^{d}$ we have that $b\left(a_{\tau^{d}}, \tau^{d}\right)=L_{\tau^{d}}$ as $a_{\tau^{d}}=A$, and for $\tau=\tau^{f}$ we have $b\left(a_{\tau^{f}}, \tau^{f}\right)=0$ as $a_{\tau^{f}}=v_{\tau^{f}}$. Using this, and the definition of process $G$, 
we have that under any arbitrary incentive compatible allocation $\left(\tau^{f}, \tau^{d}, I, C, Y\right)$ and any $t \in[0, \infty)$ :

$$
\begin{gathered}
E\left[\int_{0}^{\tau} e^{-r s}\left(d Y_{s}-d I_{s}\right)+e^{-r \tau}\left[1_{\tau=\tau_{s}^{*}} L_{\tau}^{S}+1_{\tau=\tau^{d}} L_{\tau}\right]\right]= \\
E\left[G_{t \wedge \tau}\right]+E\left[1_{t \leq \tau}\left(\int_{t}^{\tau} e^{-r s}\left(d Y_{s}-d I_{s}\right)+e^{-r \tau}\left[1_{\tau=\tau_{s}^{*}} L_{\tau}^{S}+1_{\tau=\tau^{d}} L_{\tau}\right]-e^{-r t} b\left(a_{t}, t\right)\right)\right] \leq \\
b_{0}\left(a_{0}, 0\right)+E\left[1_{t \leq \tau}\left(\int_{t}^{\tau} e^{-r s}\left(d Y_{s}-d I_{s}\right)+e^{-r \tau}\left[1_{\tau=\tau_{s}^{*}} L_{\tau}^{S}+1_{\tau=\tau^{d}} L_{\tau}\right]-e^{-r t} b\left(a_{t}, t\right)\right)\right]= \\
b_{0}\left(a_{0}, 0\right)+e^{-r t} E\left[1_{t \leq \tau}\left(E\left[\int_{t}^{\tau} e^{r(t-s)}\left(d Y_{s}-d I_{s}\right)+e^{r(t-\tau)}\left[1_{\tau=\tau_{s}^{*}} L_{\tau}^{S}+1_{\tau=\tau^{d}} L_{\tau}\right] \mid \mathcal{F}_{t}\right]-b\left(a_{t}, t\right)\right)\right],
\end{gathered}
$$

where, the inequality follows from the fact that $G_{t \wedge \tau}$ is supermartingale and $G_{0}=b_{0}\left(a_{0}, 0\right)$. We note that in the above

$$
E\left[\int_{t}^{\tau} e^{r(t-s)}\left(d Y_{s}-d I_{s}\right)+e^{r(t-\tau)}\left[1_{\tau=\tau_{s}^{*}} L_{\tau}^{S}+1_{\tau=\tau^{d}} L_{\tau}\right] \mid \mathcal{F}_{t}\right]<\frac{\mu}{r}+P_{t_{s}^{*}}-\left(a_{t}-\frac{\theta}{r}\right),
$$

as the RHS of the above inequality is the upper bound on the lender's expected profit under the first-best (public information) allocation. Using the above inequality in (34) we have that

$E\left[\int_{0}^{\tau} e^{-r s}\left(d Y_{s}-d I_{s}\right)+e^{-r \tau}\left[1_{\tau=\tau_{s}^{*}} L_{\tau}^{S}+1_{\tau=\tau^{d}} L_{\tau}\right]\right] \leq b_{0}\left(a_{0}, 0\right)+e^{-r t} E\left[1_{t \leq \tau}\left(\frac{\mu}{r}+\frac{\theta}{r}+P_{t_{s}^{*}}-a_{t}-b\left(a_{t}, t\right)\right)\right]$.

Using $b^{\prime}(a, t) \geq-1$, we have that, for any $a \geq A,-a-b(a, t) \leq-A-L_{t}$. Applying this to the above inequality yields

$$
E\left[\int_{0}^{\tau} e^{-t s}\left(d Y_{s}-d I_{s}\right)+e^{-r \tau}\left[1_{\tau=\tau_{s}^{*}} L_{\tau}^{S}+1_{\tau=\tau^{d}} L_{\tau}\right]\right] \leq b_{0}\left(a_{0}, 0\right)+e^{-r t} E\left[1_{t \leq \tau}\left(\frac{\mu}{r}+\frac{\theta}{r}+P_{t_{s}^{*}}-A-L\right)\right] .
$$

Taking $t \rightarrow \infty$ yields

$$
E\left[\int_{0}^{\tau} e^{-t s}\left(d Y_{s}-d I_{s}\right)+e^{-r \tau}\left[1_{\tau=\tau_{s}^{*}} L_{\tau}^{S}+1_{\tau=\tau^{d}} L_{\tau}\right]\right] \leq b_{0}\left(a_{0}, 0\right)
$$

Let $\left(\tau^{f *}, \tau^{d *}, I^{*}, C^{*}, Y\right)$ be an allocation satisfying the conditions of the proposition. We remember that this allocation is incentive compatible as it is feasible and $\beta_{t}=\sigma \geq \sigma$ for any $t \leq \tau$. Also under this allocation 
the process $G_{t}$ is a martingale until time $\tau$ (note that $b^{\prime}(a, t)$ is bounded). So we have that

$$
\begin{gathered}
E\left[\int_{0}^{\tau^{*}} e^{-R_{s}}\left(d Y_{s}-d I_{s}^{*}\right)+e^{-r \tau^{*}}\left[1_{\tau=\tau_{s}^{*}} L_{\tau}^{S}+1_{\tau=\tau^{* d}} L_{\tau}\right]\right]= \\
b_{0}\left(a_{0}, 0\right)+e^{-r t} E\left[1_{t \leq \tau^{*}}\left(E\left[\int_{t}^{\tau^{*}} e^{r(t-s)}\left(d Y_{s}-d I_{s}^{*}\right)+e^{r\left(t-\tau^{*}\right)}\left[1_{\tau^{*}=\tau_{s}^{*}} L_{\tau}^{S}+1_{\tau^{*}=\tau^{*} d} L_{\tau}\right] \mid \mathcal{F}_{t}\right]-b\left(a_{t}, t\right)\right)\right] .
\end{gathered}
$$

Taking $t \rightarrow \infty$ and using

$$
\lim _{t \rightarrow \infty} e^{-r t} E\left[1_{t \leq \tau^{*}}\left(E\left[\int_{t}^{\tau^{*}} e^{r(t-s)}\left(d Y_{s}-d I_{s}^{*}\right)+e^{r\left(t-\tau^{*}\right)}\left[1_{\tau^{*}=\tau_{s}^{*}} L_{\tau}^{S}+1_{\tau^{*}=\tau^{* d}} L_{\tau}\right] \mid \mathcal{F}_{t}\right]-b\left(a_{t}, t\right)\right)\right]=0,
$$

yields

$$
E\left[\int_{0}^{\tau^{*}} e^{-r s}\left(d Y_{s}-d I_{s}^{*}\right)+e^{-r \tau^{*}}\left[1_{\tau^{*}=\tau_{s}^{*}} L_{\tau}^{S}+1_{\tau^{*}=\tau^{* d}} L_{\tau}\right]\right]=b\left(a_{0}, 0\right)
$$

\section{Proof of Proposition 6}

Let $(C, \hat{Y})$ be any borrower's feasible strategy given the allocation $\zeta=\left(\tau^{f}, \tau^{d}, I\right)$. The borrower's private saving's account balance, $S$, under the strategy $(C, \hat{Y})$ and the allocation $\zeta$ grows, for $t \in[0, \tau]$, according to

$$
d S_{t}=\rho S_{t} d t+\left(d Y_{t}-d \hat{Y}_{t}\right)+d I_{t}-d C_{t},
$$

where we remember that $\rho \leq r$. Define the process $\hat{V}$ as

$$
\hat{V}_{t}=\int_{0}^{t} e^{-r s} d C_{s}+\int_{0}^{t} e^{-r s} \theta d s+e^{-r t}\left(S_{t}+a_{t}\right)
$$

From the above it follows that

$$
e^{r t} d \hat{V}_{t}=d C_{t}+\theta d t+d S_{t}-r S_{t} d t+d a_{t}-r a_{t} d t
$$

Using (22) and (35) yields

$$
\begin{aligned}
e^{r t} d \hat{V}_{t}= & (\rho-r) S_{t} d t+\left(d Y_{t}-\mu d t\right) d t+\psi_{t} d M_{t}= \\
& (\rho-r) S_{t} d t+\sigma d Z_{t}+\psi_{t} d M_{t} .
\end{aligned}
$$


Noting that $e^{r t} \geq 1$ for any $t \geq 0$, so we have that

$$
d \hat{V}_{t} \leq(\rho-r) S_{t} d t+\sigma d Z_{t}+\psi_{t} d M_{t}
$$

Recall that $Z$ and $M$ are martingales, $\rho \leq r$, and that the process $S$ is nonnegative. So it follows from the above that the process $\hat{V}$ is supermartingale up to time $\tau$ (note that $a$ is bounded from below). Using this and the fact that by definition $a_{\tau^{d}}=A, a_{\tau^{f}}=v_{\tau^{f}}, a_{\tau_{s}^{*}}=A_{t_{s}^{*}}^{S}\left(a_{t_{s}^{*}}\right)$ we have that for any feasible strategy of the borrower,

$$
a_{0}=\hat{V}_{0} \geq E\left[\hat{V}_{\tau}\right]=E\left[\int_{0}^{\tau} e^{-r s} d C_{s}+\int_{0}^{\tau} e^{-r s} \theta d s+e^{-r \tau}\left(S_{\tau}+1_{\tau=\tau_{s}^{*}} A_{\tau}^{S}+1_{\tau=\tau^{f}} v_{\tau}+1_{\tau=\tau^{d}} A\right)\right],
$$

The right-hand-side of (37) represents the expected utility for the borrower under any feasible $(C, \hat{Y}, S)$. This utility is bounded by $a_{0}$. If the borrower maintains zero savings, $S_{t}=0$, reports cash flows truthfully, $d \hat{Y}_{t}=d Y_{t}$, then $\hat{V}$ is a martingale up to time $\tau$, which means that (37) holds with equality and the borrower's expected utility is $a_{0}$. Thus, this is the optimal strategy for the borrower.

\section{Proof of Proposition 7}

Consider the candidate mortgage contract. Under this contract the borrower's balance on the credit line evolves according to

$$
d B_{t}=\bar{r}_{t} B_{t} d t-s_{t}\left(B_{t}\right)+i_{t}\left(B_{t}\right)-d \hat{Y}_{t}+d I_{t}+B A_{t} d N_{t}
$$

when $B_{t} \leq C_{t}^{L}$, while the borrower's savings evolve according to

$$
d S_{t}=\rho S_{t} d t+d I_{t}+\left(d Y_{t}-d \hat{Y}_{t}\right)-d C_{t}
$$

where $I_{t}$ represents cumulative withdrawal of money from the credit line by the borrower.

Let $(C, \hat{Y}, S)$ be any borrower's feasible strategy under the proposed mortgage contract. For any feasible borrower's strategy $(C, \hat{Y}, S)$ define a process $\hat{V}$ as

$$
\hat{V}_{t}=\int_{0}^{t} e^{-r s}\left(d C_{s}+\theta d s\right)+e^{-r t}\left(\tilde{a}_{t}+S_{t}\right)
$$

where

$$
\tilde{a}_{t}=v_{t}-B_{t}
$$


It follows from (38), (41), and (23)-(28) that $\tilde{a}$ evolves as

$$
d \tilde{a}_{t}=\left(r \tilde{a}_{t}-\theta-\delta\left(N_{t}\right) \psi\left(\tilde{a}_{t}, t\right)\right) d t+\left(d \hat{Y}_{t}-\mu d t\right)-d I_{t}+\psi\left(\tilde{a}_{t}, t\right) d N_{t}
$$

Using (1), (39), (40), (42) yields

$$
\begin{aligned}
e^{r t} d \hat{V}_{t} & =d C_{t}+\theta d t+d \tilde{a}_{t}+d S_{t}-r \tilde{a}_{t} d t-r S_{t} d t \\
& =\sigma d Z_{t}+\psi\left(\tilde{a}_{t}, t\right) d M_{t}+(\rho-r) S_{t} d t
\end{aligned}
$$

Recall that $Z$ and $M$ are martingales, $\rho<r$, and that the process $S$ is nonnegative. So it follows from the above that the process $\hat{V}$ is a supermartingale up to time $\tau(C, \hat{Y}, S)=\min \left(\tau_{s}^{*}, \tau^{f}(C, \hat{Y}, S), \tau^{d}(C, \hat{Y}, S)\right)$ (note that $\tilde{a}$ is bounded). Using this and the fact that by definition $\tilde{a}_{\tau^{d}}=A$ and $\tilde{a}_{\tau^{f}}=v_{t}$ we have that for any feasible strategy of the borrower, $(C, \hat{Y}, S)$,

$$
\begin{gathered}
A+C_{0}^{L}-B_{0}=a_{0}=\tilde{a}_{0}=\hat{V}_{0} \geq E\left[\hat{V}_{\tau(C, \hat{Y}, S)]}\right. \\
=E\left[\int_{0}^{\tau(C, \hat{Y}, S)} e^{-r s}\left(d C_{s}+\theta d s\right)+e^{-r \tau}\left(S_{\tau(C, \hat{Y}, S)}+1_{\tau(C, \hat{Y}, S)=\tau_{s}^{*}} A_{\tau}^{S}+1_{\tau(C, \hat{Y}, S)=\tau^{f}} v_{\tau}+1_{\tau(C, \hat{Y}, S)=\tau^{d}} A\right)\right]
\end{gathered}
$$

The right-hand-side of (43) represents the expected utility for the borrower under any feasible strategy $(C, \hat{Y}, S)$, given the terms of the mortgage. This utility is bounded by $A+C_{0}^{L}-B_{0}$, where $B_{0}$ is the initial draw on the credit line. If the borrower maintains zero savings, $S_{t}=0$, uses all its cash flow for repayment till his mortgage balance reaches zero, $d \hat{Y}_{t}=d Y_{t}$, so that $d C_{t}=d I_{t}=d I_{t}^{*}=0$, then $\hat{V}$ is a martingale, which means that (43) holds with equality and the borrower's expected utility is $A+C_{0}^{L}-B_{0}$. Thus, this is the optimal strategy for the borrower.

Reproducing the above argument for the borrower's optimal strategy, $(C, \hat{Y}, S)=\left(I^{*}, Y, 0\right)$, and the process $\hat{V}_{t^{\prime}}, t^{\prime} \leq \tau\left(I^{*}, Y, 0\right)$, defined as

$$
\hat{V}_{t^{\prime}, t}=\int_{t^{\prime}}^{t} e^{-r\left(s-t^{\prime}\right)}\left(d C_{s}+\theta d s\right)+e^{-r\left(t-t^{\prime}\right)} \tilde{a}_{t}, \quad t \geq t^{\prime},
$$

yields that, for any $0 \leq t \leq \tau\left(I^{*}, Y, 0\right), \tilde{a}_{t}$ is equal to the borrower's continuation utility under the proposed mortgage contract with the initial expected utility for the borrower given by $a_{0}=A+C_{0}^{L}-B_{0}$, which establishes (29).

Under the proposed mortgage contract and the borrower's optimal strategy, the lender's expected utility 
equals

$$
E\left[\int_{0}^{\tau\left(I^{*}, Y, 0\right)} e^{-r t}\left(d Y_{t}-d I_{t}^{*}\right)+e^{-r \tau\left(I^{*}, Y, 0\right)}\left[1_{\tau\left(I^{*}, Y, 0\right)=\tau_{s}^{*}} L_{\tau}^{S}+1_{\tau\left(I^{*}, Y, 0\right)=\tau^{d}} L_{\tau}\right] \mid \mathcal{F}_{0}\right]
$$

where

$$
\tau\left(I^{*}, Y, 0\right)=\tau^{*},
$$

as the borrower's continuation utility, $\tilde{a}$, evolve according to the equations (21) in the boom and (13) in the slump, e.g. as in the optimal allocation. Therefore, we conclude that the proposed mortgage contract implements the optimal allocation. 


\section{References}

Adrian, Tobias, and Mark WesterfieldDisagreement and Learning in a Dynamic Contracting Model with Tobias Adrian. Revised 8-30-07

Abreu, Dilip, David Pearce, and Ennio Stacchetti, 1990, Toward a theory of discounted repeated games with imperfect monitoring, Econometrica 58, 1041-63.

Agarwal, Sumit, and Calvin T. Ho (August 2007), Comparing the prime and subprime mortgage markets, Chicago Fed Letter, Number 241

Ambrose, Brent W., Richard J. Buttimer, and Charles A. Capone, 1997, Pricing mortgage default and foreclosure delay, Journal of Money, Credit and Banking 29, 314-25.

Ait-Sahalia, Yacine, Jonathan Parker, and Motohiro Yogo, 2004, Luxury goods and the equity premium, Journal of Finance 59, 2959-3004.

Biais, Bruno, Thomas Mariotti, Guillaume Plantin, and Jean-Charles Rochet, 2007, Dynamic security design: Convergence to continuous time and asset pricing implications, Review of Economic Studies $74,345-390$

Brueckner, Jan K., 1994, Borrower mobility, adverse selection, and mortgage points, Journal of Financial Intermediation 3, 416-441.

Campbell, John Y., João F. Cocco, Francisco Gomes, and Pascal Maenhout, 2000, Investing retirement wealth: A life-cycle model, in John Campbell and Martin Feldstein, eds.: Risk Aspects of Social Security Reform (The University of Chicago Press).

Campbell, John Y., and João F. Cocco, 2003, Household risk management and optimal mortgage choice, Quarterly Journal of Economics 118, 1449-1494.

Clementi, Gian Luca, and Hugo A. Hopenhayn, 2006, A theory of financing constraints and firm dynamics, Quarterly Journal of Economics 121, 229-265.

Chari, Varadarajan V., and Ravi Jagannathan, 1989, Adverse selection in a model of real estate lending, Journal of Finance 44, 499-508.

Deng, Yongheng, John M. Quigley, and Robert Van Order, 2000, Mortgage Terminations, Heterogeneity and the Exercise of Mortgage Options, Econometrica, 68, 275-308.

DeMarzo, Peter M., and Michael J. Fishman, 2004, Optimal long-term financial contracting with privately observed cash flows, working paper. 
DeMarzo, Peter M., and Michael J. Fishman, 2007, Agency and optimal investment dynamics, Review of Financial Studies 20, 151-188.

DeMarzo, Peter M., and Yuliy Sannikov, 2006, A continuous-time agency model of optimal contracting and capital structure, Journal of Finance 61, 2681-2724.

DeMarzo, Peter M., Michael J. Fishman, Zhiguo He, and Neng Wang, 2007, Dynamic agency and the q theory of investment, working paper.

Dunn, Kenneth B., and Chester S. Spatt, 1985, Prepayment penalties and the due-on-sale clause, Journal of Finance 40, 293-308.

Freddie Mac, 2007, Primary Mortgage Market Survey, June 21, 2007.

Getter, Darryl E., 2003, Contributing to the delinquency of borrowers, Journal of Consumer Affairs 37, 86-100.

Gerardi, Kristopher, Harvey S. Rosen, and Paul Willen, 2007, Do households benefit from financial deregulation and innovation? The Case of the Mortgage Market, NBER Working Paper No. 12967.

Green, Edward J., 1987, Lending and the smoothing of uninsurable income, in Edward C. Prescott and Neil Wallace, eds.: Contractual Arrangements for Intertemporal Trade (Minneapolis: University of Minnesota Press).

He, Zhiguo, 2007, Optimal executive compensation when firm size follows geometric Brownian motion, forthcoming in the Review of Financial Studies.

Joint Economic Committee, 2007, Sheltering Neighborhoods From the Subprime Foreclosure Storm, Joint Economic Committee Report, April, 11, 2007.

Kau, James B., Donald C. Keenan, Walter J. Muller, III, James F. Epperson, 1992, A Generalized Valuation Model for Fixed-Rate Residential Mortgages, Journal of Money, Credit and Banking, 24, 279-299.

LeRoy, Stephen F., 1996, Mortgage valuation under optimal prepayment, Review of Financial Studies 9, $817-844$.

Lustig, Hanno, and Stijn Van Nieuwerburgh, 2006, How much does household collateral constrain regional risk sharing?, working paper.

Jacod, Jean, and Albert N. Shiryaev, 2003, Limit Theorems for Stochastic Processes, 2nd ed. (New York, NY: Springer-Verlag).

New York Times, 2007, Other reasons borrowers falter, by Bob Tedeschi, Published: May 6, 2007. 
Phelan, Christopher, and Robert M. Townsend, 1991, Computing multi-period, information-constrained optima, Review of Economic Studies 58, 853-881.

Philippon, Thomas and Yuliy Sannikov, 2007, Real options in a dynamic agency model, with applications to financial development, IPOs, and business risk, working paper NYU Stern.

Piskorski, T., and A. Tchistyi, 2007, Optimal mortgage design, working paper, Columbia Business School and NYU Stern.

Posey, Lisa L., and Abdullah Yavas, 2001, Adjustable and fixed rate mortgages as a screening mechanism for default risk, Journal of Urban Economics 49, 54-79.

Sannikov, Yuliy, 2006a, A continuous-time version of the principal-agent problem, working paper, University of California at Berkeley.

Sannikov, Yuliy, 2006b, Agency problems, screening and increasing credit lines, working paper, University of California at Berkeley.

Spear, Stephen E., and Sanjay Srivastava, 1987, On repeated moral hazard with discounting, Review of Economic Studies 53, 599-617.

Stanton, Richard H., and Nancy Wallace, 1998, Mortgage choice: What is the point?, Real Estate Economics 26, 173-205.

Tchistyi, Alexei, 2006, Security design with correlated hidden cash flows: The optimality of performance pricing, working paper, NYU Stern.

Wall Street Journal, 2005, The prepayment trap: Lenders put penalties on popular mortgages, by Ruth Simon, Published: March 10, 2005. 